\title{
Impact of Tetrabutylammonium on the Oxidation of Bromide by Ozone
}

\author{
Shuzhen Chen, Luca Artiglia, Fabrizio Orlando, Jacinta Edebeli, Xiangrui Kong, Huanyu Yang, \\ Anthony Boucly, Pablo Corral Arroyo, Nønne Prisle, and Markus Ammann*
}

Cite This: ACS Earth Space Chem. 2021, 5, 3008-3021

Read Online

\section{ACCESS |}

Џlll Metrics \& More

Article Recommendations

Supporting Information

ABSTRACT: The reaction of ozone with sea-salt derived bromide is relevant for marine boundary layer atmospheric chemistry. The oxidation of bromide by ozone is enhanced at aqueous interfaces. Ocean surface water and sea spray aerosol are enriched in organic compounds, which may also have a significant effect on this reaction at the interface. Here, we assess the surface propensity of cationic tetrabutylammonium at the aqueous liquid-vapor interface by liquid microjet X-ray photoelectron spectroscopy (XPS) and the effect of this surfactant on ozone uptake to aqueous bromide solutions. The results clearly indicate that the positively charged nitrogen group in tetrabutylammonium (TBA), along with its surface activity, leads to an enhanced interfacial concentration

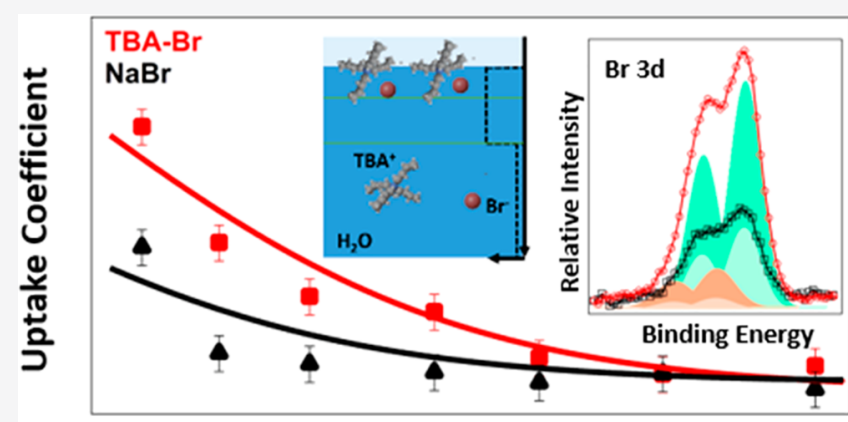

Ozone Concentration of both bromide and the bromide ozonide reaction intermediate. In parallel, off-line kinetic experiments for the same system demonstrate a strongly enhanced ozone loss rate in the presence of TBA, which is attributed to an enhanced surface reaction rate. We used liquid jet XPS to obtain detailed chemical composition information from the aqueous-solution-vapor interface of mixed aqueous solutions containing bromide or bromide and chloride with and without TBA surfactant. Core level spectra of $\mathrm{Br} 3 \mathrm{~d}, \mathrm{C} 1 \mathrm{~s}, \mathrm{Cl} 2 \mathrm{p}, \mathrm{N} 1 \mathrm{~s}$, and $\mathrm{O} 1 \mathrm{~s}$ were used for this comparison. A model was developed to account for the attenuation of photoelectrons by the carbon-rich layer established by the TBA surfactant. We observed that the interfacial density of bromide is increased by an order of magnitude in solutions with TBA. The salting-out of TBA in the presence of $0.55 \mathrm{M}$ sodium chloride is apparent. The increased interfacial bromide density can be rationalized by the association constants for bromide and chloride to form ion-pairs with TBA. Still, the interfacial reactivity is not increasing simply proportionally with the increasing interfacial bromide concentration in response to the presence of TBA. The steady state concentration of the bromide ozonide intermediate increases by a smaller degree, and the lifetime of the intermediate is 1 order of magnitude longer in the presence of TBA. Thus, the influence of cationic surfactants on the reactivity of bromide depends on the details of the complex environment at the interface.

KEYWORDS: tetrabutylammonium, bromide, ozone, surface propensity, ion-pairs, X-ray photoelectron spectroscopy, liquid jet, halogen chemistry

\section{INTRODUCTION}

In atmospheric science, halogen chemistry and its impact on the ozone budget remains a hot topic. ${ }^{1-3}$ The halide-solutionair interfaces associated with seawater and sea spray aerosol are especially important, because about $71 \%$ of the Earth's surface is covered by seawater, which represents a substantial reservoir for chloride, bromide, and iodide. Multiphase reactions between gas-phase species and halides in seawater are centrally important, because they lead to activation of halogen species to the gas phase. ${ }^{4,5}$ Cycling of these halogen species exerts a powerful influence on the chemical composition of the troposphere. It has been estimated that halogen chemistry contributes $50 \%$ of the chemical sink for tropospheric ozone globally. ${ }^{6}$ It may affect the global oxidation capacity, the fate of pollutants and tropospheric ozone (including its radiative impact), and the production of particles. ${ }^{4,5}$ Particle phase halogen species also contribute to ozone loss in the stratosphere. ${ }^{7}$

The multiphase oxidation of bromide $\left(\mathrm{Br}^{-}\right)$by $\mathrm{O}_{3}$ is a significant dark source of hypobromic acid ( $\mathrm{HOBr}$ ) when shorter-lived photochemically produced radicals and oxidants are not abundant. ${ }^{6,8}$ These initial bromide oxidation processes are the starting point of the multiphase cycling reactions that

Special Issue: Mario Molina Memorial

Received: June 29, 2021

Revised: October 1, 2021

Accepted: October 9, 2021

Published: October 26, 2021

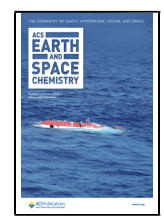


lead to the release of bromine, thus bromine activation. Under the special circumstances of the spring-time polar marine boundary layer, bromine activation is a strong component of local and episodic $\mathrm{O}_{3}$ depletion.'

Ocean surface water and sea spray aerosol often contain complex mixtures of organics derived from marine biota with variable surface affinity and functionalities, such as proteins, carbohydrates, phospholipids, and fatty acids. ${ }^{10-12}$ Surface active organics may affect multiphase chemical reactions by changing the interfacial activity of the halide ions or of reaction intermediates ${ }^{13,14}$ or actively engage in chemistry and photochemistry. ${ }^{15,16}$ Such effects have not been sufficiently elucidated, mostly because of the lack of studies selectively probing the interfacial region and processes thereon.

The kinetics of multiphase reactions initiated by gas phase oxidants are described by the uptake coefficient, $\gamma$, defined as the ratio of the net flux of molecules from the gas phase to the condensed phase divided by the gas-kinetic collision flux of the molecules to the surface of the condensed phase. ${ }^{17}$ The multiphase reaction of $\mathrm{O}_{3}$ with $\mathrm{Br}^{-}$ions to $\mathrm{HOBr}$ has been studied for two decades and suggested to be enhanced at the aqueous solution-air interface. ${ }^{18-26}$ In aqueous solution, Liu et al. $^{27}$ suggested that the mechanism involves a bromide ozonide as an intermediate (R1), which then decomposes into molecular oxygen (R2 and $\mathrm{R} 3$ ) and $\mathrm{HOBr}$ in an acid assisted step. $\mathrm{HOBr}$ then reacts further with $\mathrm{Br}^{-}$, again in an acid catalyzed reaction, to form $\mathrm{Br}_{2}$ (R4). Nevertheless, the reason for the surface enhanced reactivity had remained elusive.

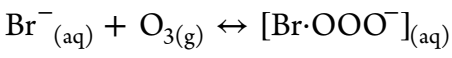

$$
\begin{aligned}
& {\left[{\left.\mathrm{Br} \cdot \mathrm{OOO}^{-}\right]_{(\mathrm{aq})}+\mathrm{H}^{+}(\mathrm{aq})}_{\mathrm{HOBr}_{(\mathrm{aq})}}+\mathrm{O}_{2(\mathrm{~g})}\right.} \\
& {\left[\mathrm{Br} \cdot \mathrm{OOO}^{-}\right]_{(\mathrm{aq})}+\mathrm{H}_{2} \mathrm{O}_{(\mathrm{l})} \leftrightarrow \mathrm{HOBr}_{(\mathrm{aq})}+\mathrm{O}_{2(\mathrm{~g})}+\mathrm{OH}_{(\mathrm{aq})}^{-}}
\end{aligned}
$$

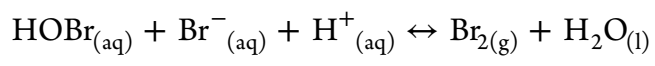

The traditional approach to study the chemical composition at the aqueous solution-air interface through the contribution of constituents to the surface free energy is via recording the surface tension as a function of solute concentration. ${ }^{28}$ However, this is not straightforward for complex solutions, because the synergistic effects and their composition dependence make it extremely difficult to assign concentration dependent contributions to the surface tension for individual components in solution. Both chemical composition and processes at interfaces can be characterized by X-ray photoelectron spectroscopy (XPS), which provides both chemical selectivity and surface sensitivity. ${ }^{29}$ Liquid jet XPS directly provides the composition of inorganic and organic compounds at the aqueous solution-vapor interface within the topmost molecular layers of the liquid. ${ }^{30-33}$ Using this technique, supporting theoretical calculation and additional kinetic experiments, Artiglia et al. ${ }^{20}$ reported direct experimental evidence for the ozonide in $\mathrm{R} 1$ and found it to exhibit a high propensity for the liquid-vapor interface. This surface active intermediate turned out to be the cause of the surface enhanced reaction rate, rather than the debated abundance of bromide itself at the interface. ${ }^{34}$

In an attempt to address the impact of organics on the oxidation of bromide by $\mathrm{O}_{3}$, Lee et al. ${ }^{35}$ recently studied the reaction of bromide with ozone in the presence and absence of citric acid, a proxy for highly functionalized organic compounds in the atmosphere, under ambient conditions. With citric acid, the uptake kinetics of $\mathrm{O}_{3}$ was faster than that predicted by bulk reaction-limited uptake and also faster than expected on the basis of an acid-catalyzed mechanism. Parallel liquid jet XPS revealed that bromide became depleted by around $30 \%$ within the probe depth of the experiment of around $1 \mathrm{~nm}$. In 2019, Lee et al. ${ }^{33}$ found an opposing effect of butanol and butyric acid on the abundance of bromide and iodide at the liquid-vapor interface. In comparison to the pure aqueous halide solution, 1-butanol increased the interfacial density of bromide by $25 \%$, while butyric acid reduced it by $40 \%$, respectively, which is probably controlled by a subtle interplay of electrostatic, dipole, and hydrogen bonding interactions. Therefore, looking at the effects of surfactant cosolutes with different properties is an important task for better constraining the interfacial reactivity of halides under environmental conditions.

Tetrabutylammonium (TBA) may be considered as a proxy for atmospherically relevant organic amines and other cationic surfactants derived from biogenic oceanic material. ${ }^{12,36}$ Its amphiphilic character with aliphatic side chains makes it strongly surface-active in aqueous solution. On the basis of surface tension measurements, TBA bromide is expected to exhibit a surface excess of $\sim 3.0 \times 10^{14}$ molecules per $\mathrm{cm}^{2}$ at 0.1 $\mathrm{M}^{13}$ TBA exhibits also a strong ion-pairing capacity, which makes TBA ions important in various areas of chemistry, e.g., in phase-transfer catalysis, where relatively hydrophobic cations are used for precipitating large anions. ${ }^{37}$ Several studies have addressed the interfacial properties of TBA containing iodide solutions (including mixtures with bromide) with VUV photoemission. ${ }^{38-41}$ Also molecular beam scattering experiments of $\mathrm{N}_{2} \mathrm{O}_{5}$ interacting with a liquid jet containing tetraalkylammonium surfactants indicated interactions between the positively charged surfactant and reactants or products, also depending on the solvent. ${ }^{42,43}$ Overall, the details of how charged surfactant ions affect the halide ions, their reactivity, and potentially also reaction products have remained open.

In this work, we used liquid jet XPS to directly assess the impact of TBA on the abundance of bromide and the bromide ozonide at the aqueous solution-air interface and to compare the spectroscopic information with the results of $\mathrm{O}_{3}$ uptake kinetic experiments performed in parallel.

\section{EXPERIMENTAL SECTION}

Materials. This study was conducted using sodium bromide (NaBr, Sigma-Aldrich, > 99.0\%), sodium chloride $(\mathrm{NaCl}$, Sigma-Aldrich, > 99.0\%), and tetrabutylammonium bromide (TBA-Br, Sigma-Aldrich, > 99.0\%) without further purification. Sample solutions were prepared by adding stock solutions to Milli-Q water (Millipore, $18.2 \mathrm{M} \Omega \mathrm{cm}$ at $25{ }^{\circ} \mathrm{C}$ ). $\mathrm{NaBr}(0.1 \mathrm{M}), 0.1 \mathrm{M} \mathrm{NaBr} / 0.55 \mathrm{M} \mathrm{NaCl}, 0.1 \mathrm{M}$ TBA-Br, 0.1 $\mathrm{M}$ TBA-Br/0.55 M NaCl, and 0.1 M TBA-Br/0.1 M NaBr/ $0.55 \mathrm{M} \mathrm{NaCl}$ aqueous solutions were prepared for liquid jet XPS and kinetic experiments.

Liquid Microjet X-ray Photoelectron Spectroscopy (XPS). XPS experiments using a liquid microjet were conducted at the Surfaces/Interfaces: Microscopy (SIM) beamline of the Swiss Light Source (SLS) ${ }^{44}$ using the near ambient pressure photoemission (NAPP) endstation. ${ }^{44,45}$ The electron analyzer uses a three-stage differentially pumped electrostatic lens system (Scienta HiPP-2) and a hemispherical analyzer (Scienta R4000) to collect photoelectrons from 
samples in chamber pressures up to a few millibar. For the present experiments, a quartz nozzle (MicroLiquids), forming a liquid microjet with a diameter of $25 \mu \mathrm{m}$, was used to deliver a liquid sample into the analysis chamber.

The liquid jet was operated with a flow rate of $0.5 \mathrm{~mL} / \mathrm{min}$. The capillary transporting the liquid was immersed in a cooling bath set to $277 \mathrm{~K}$ upstream of the feedthrough into the chamber. The characterization of aqueous solutions, without gas dosing, was performed in a vacuum $\left(1.0 \times 10^{-3}-1.0 \times\right.$ $\left.10^{-4} \mathrm{mbar}\right)$. The diameter of the entrance orifice of the electron sampling aperture into the prelens and the working distance to the liquid jet were both $500 \mu \mathrm{m}$. The electron analyzer was operated at $20 \mathrm{eV}$ pass energy (photoelectron kinetic energy at $155 \mathrm{eV}$ ) and $50 \mathrm{eV}$ pass energy (photoelectron kinetic energy at $370 \mathrm{eV}$ ) with a $0.1 \mathrm{eV}$ step size. The liquid filament position was adjusted to spatially overlap with the $100 \mu \mathrm{m}$ (vertical) by $60 \mu \mathrm{m}$ (horizontal) synchrotron light beam. ${ }^{44}$ Optimum alignment was achieved by monitoring the condensed phase $\mathrm{O} 1 \mathrm{~s}$ at $900 \mathrm{eV}$ photon energy.

For experiments, in which the liquid jet was exposed to gas phase $\mathrm{O}_{3}$, we used a gas delivery system, which has been described in our previous work. ${ }^{20}$ In brief, a second gas nozzle was fixed concentrically around the quartz nozzle delivering the liquid. The second gas nozzle reaches about $0.1 \mathrm{~mm}$ beyond the liquid jet nozzle. The gas starts to interact with the liquid wire from the end of the quartz nozzle delivering the liquid jet before expansion into the vacuum chamber at the end of the second nozzle. The admitted gas was either pure oxygen or a mixture of up to a few percents of ozone in oxygen. Before dosing the gas, the pressure in the experimental chamber was raised to $1 \times 10^{-3}$ mbar (with the turbo molecular pump stopped and a $\mathrm{SiN}_{x}$ window mounted between the X-ray beamline and the liquid jet chamber). While dosing the gas, the pressure was set to $0.25 \mathrm{mbar}$ by means of a leak valve connected to the gas nozzle via a $1 / 16^{\prime \prime}$ PEEK tube, leading to a gas flow rate of around $15 \mathrm{sccm} / \mathrm{min}$. Ozone was generated online by means of a home-built corona discharge ozone generator. We varied the ozone concentration by changing the flow rate of $\mathrm{O}_{2}$ through the corona discharge unit in the range $2-12 \mathrm{~mL} / \mathrm{min}$. The corresponding change in the dilution ratio (around 1:7000) was taken into account for the ozone concentration calibration. The mixing ratio of $\mathrm{O}_{3}$ in $\mathrm{O}_{2}$ in the gas admitted to the experimental chamber was in the range $1 \%-3 \%$. The efficiency of $\mathrm{O}_{2}$ to $\mathrm{O}_{3}$ conversion in the ozone generator was checked in separate experiments by means of the same ozone analyzer, as described further below for the kinetics experiments. The gas composition in the analysis chamber with respect to the major components $\mathrm{N}_{2}, \mathrm{O}_{2}, \mathrm{H}_{2} \mathrm{O}$, and $\mathrm{CO}_{2}$ was checked by means of a quadrupole mass spectrometer installed in the second differential pumping stage of the electron analyzer.

Core level spectra of $\mathrm{Br} 3 \mathrm{~d}, \mathrm{~N} 1 \mathrm{~s}, \mathrm{C} 1 \mathrm{~s}, \mathrm{Cl} 2 \mathrm{p}$, and $\mathrm{O}$ 1s were acquired at photon energies allowing for photoelectron kinetic energies at 155 and $370 \mathrm{eV}$. Due to the high photon flux at the SIM beamline, using first order light to ionize the $\mathrm{O} 1 \mathrm{~s}$ orbital of solutions would lead to potentially damaging count rates at the detector. We therefore made use of the around $10 \%$ of photon flux associated with second order light, which simultaneously passes the monochromator, to ionize the $\mathrm{O}$ 1s orbital. Thus, the monochromator was set to 348 and 450 $\mathrm{eV}$ to obtain $\mathrm{O} 1 \mathrm{~s}$ spectra with excitation energies of 696 and $900 \mathrm{eV}$ for KE values of 155 and $370 \mathrm{eV}$, respectively. Spectra were acquired by a sequence of sweeps over the regions of each element, and sequences were repeated until sufficient signal-tonoise ratios were obtained. Signal intensity ratios within one experiment thus take into account varying jet positions that would lead to intensity changes between sequences.

Reported binding energies are relative to the vacuum level and calibrated to the $\mathrm{O} 1 \mathrm{~b}_{1}$ orbital of liquid water at 11.31 $\mathrm{eV} .{ }^{46}$ Exemplary valence spectra are shown in the Supporting Information (SI), Figure S1. The total photoionization cross section $\left(\sigma_{\text {tot }}\right)$ was calculated by considering cross sections $(\sigma)$ and asymmetry parameters $(\beta)$ as follows: ${ }^{47,48}$

$$
\sigma_{\mathrm{tot}}=\frac{\sigma}{4 \pi}(1+\beta)
$$

Core level spectra were fit using pure Gaussian functions following standard linear background subtraction, except for the $\mathrm{Br} 3 \mathrm{~d}$ spectra related to the experiments with $\mathrm{O}_{3}$, where a Shirley background was subtracted. For C 1 s, the full width at half-maximum (fwhm) of the peaks was constrained to the same value for the peaks contributed by the carbon atoms attached to the ammonium ion and by the butyl chain carbons. The spin-orbit split (SOS) for Br 3d was fixed at $1.03 \mathrm{eV}$ for both bromide in pure $\mathrm{NaBr}$ solutions and the bromide ozonide also present when dosing $\mathrm{O}_{3}{ }^{20}$ We forced the fwhm at the same value for the spin-orbit split peaks of $\mathrm{Br} 3 \mathrm{~d}\left(3 \mathrm{~d}_{3 / 2}\right.$, $\left.3 \mathrm{~d}_{5 / 2}\right)$ of bromide and of $\mathrm{Cl} 2 \mathrm{p}\left(2 \mathrm{p}_{1 / 2}, 2 \mathrm{p}_{3 / 2}\right)$ of chloride, respectively, at $1.03 \mathrm{eV}$. The fwhm of the $\mathrm{Br} 3 \mathrm{~d}$ peaks of bromide ozonide was $1.05 \mathrm{eV}$. The chemical shift between bromide and bromide ozonide was $+0.70 \mathrm{eV}^{20}$

Flow Reactor. Kinetic experiments were conducted in a flow reactor setup previously described by Lee et al..$^{35}$ and Artiglia et al. ${ }^{20}$ Briefly, the setup comprises a temperature regulated Teflon trough (surface area $=102 \mathrm{~cm}^{2}$ ) on which 15 $\mathrm{mL}$ of the reactive solution is loaded uniformly. The trough was kept at $4{ }^{\circ} \mathrm{C}$ for all experiments. Ozone was generated by $185 \mathrm{~nm}$ photolysis of $\mathrm{O}_{2}$ at different light intensities in a quartz cell at a flow rate of $400 \mathrm{~mL} / \mathrm{min} \mathrm{O}_{2}$ and then mixed with 2000 $\mathrm{mL} / \mathrm{min} \mathrm{N}_{2}$ (all flow rates given for $1 \mathrm{~atm}$ and $0{ }^{\circ} \mathrm{C}$ ). Part of this gas flow $(980 \mathrm{~mL} / \mathrm{min})$ was humidified to the saturation water vapor pressure at the temperature of the trough before admission to the trough. The gas flow was alternated between a bypass to measure the initial $\mathrm{O}_{3}$ concentration and the trough to measure the $\mathrm{O}_{3}$ concentration remaining after reactive uptake by the solution. The $\mathrm{O}_{3}$ concentration was measured using a commercial ozone monitor (Teledyne API model 400).

After about $1 \mathrm{~h}$ of stabilizing the background $\mathrm{O}_{3}$ concentration measured while the gas flow was bypassing the flow reactor, the gas flow was switched to the trough reactor, which led to exposure of the film to $\mathrm{O}_{3}$ allowing the multiphase reactions to take place. Finally, the concentration after the reactor was measured in bypass mode again to confirm that the background did not change during the experiment. The uptake coefficient of $\mathrm{O}_{3}, \gamma$, is equal to the rate of $\mathrm{O}_{3}$ loss to the aqueous phase divided by the gas kinetic collision rate (eq 2 ). The fractional loss of $\mathrm{O}_{3}$ was obtained from the average ozone concentration through the bypass $\left(\left[\mathrm{O}_{3}\right]_{\text {bypass }}\right)$ line measured before and after exposing the trough and that while the gas passed through the flow tube $\left(\left[\mathrm{O}_{3}\right]_{\text {flow tube }}\right)$ for each cycle. ${ }^{35}$

$$
\gamma=\frac{4 \varphi \times\left[\ln \left(\frac{\left[\mathrm{O}_{3}\right]_{\text {bypass }}}{\left[\mathrm{O}_{3}\right]_{\text {flow tube }}}\right)\right]}{\omega_{\mathrm{O}_{3}} \times \mathrm{SA}}
$$



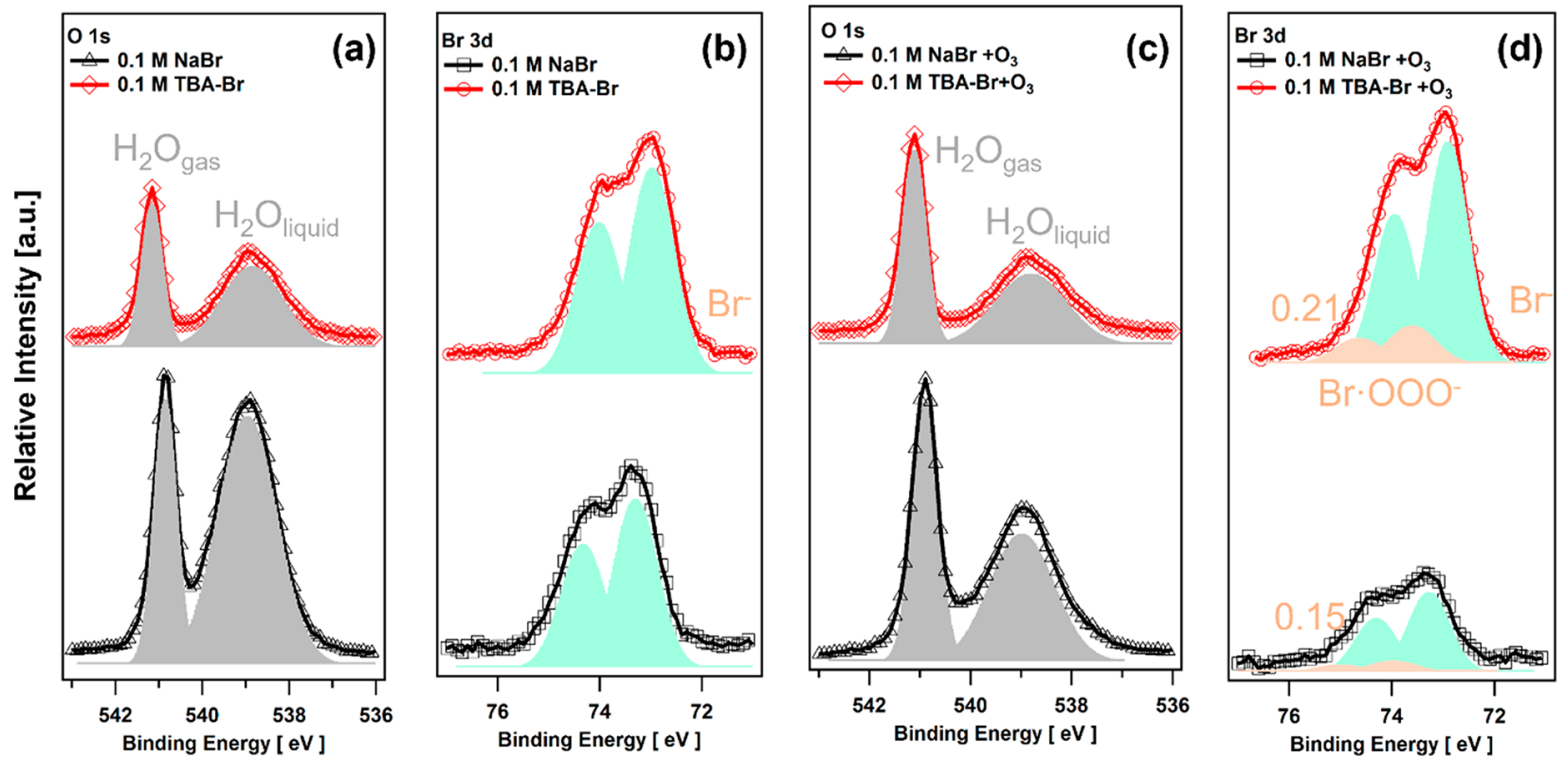

Figure 1. (a) $\mathrm{O} 1 \mathrm{~s}$ and (b) $\mathrm{Br} 3 \mathrm{~d}$ photoelectron spectra of $0.1 \mathrm{M} \mathrm{TBA}-\mathrm{Br}$ and $0.1 \mathrm{M} \mathrm{NaBr}$ aqueous solutions at photon energies of 900 and $450 \mathrm{eV}$, respectively. (c) $\mathrm{O} 1 \mathrm{~s}$ and (d) $\mathrm{Br} 3 \mathrm{~d}$ photoelectron spectra of $0.1 \mathrm{M} \mathrm{TBA}-\mathrm{Br}$ and $0.1 \mathrm{M} \mathrm{NaBr}$ aqueous solutions in the presence of $\mathrm{O}_{3}$, at photon energies of 900 and $450 \mathrm{eV}$, respectively. The spectra within each panel share the $y$-axis scale.

$$
\omega_{\mathrm{O}_{3}}=\sqrt{\frac{8 R T}{\pi M_{\mathrm{O}_{3}}}}
$$

where $\varphi$ is the flow rate of $\mathrm{O}_{3}$ through the flow tube $(980 \mathrm{~mL} /$ $\min ) ; \omega_{\mathrm{O}_{3}}$ is the mean thermal velocity of $\mathrm{O}_{3}$ in the gaseous phase $(\mathrm{cm} / \mathrm{s}) ; \mathrm{SA}$ is the exposed internal surface area of the tube; and $\mathrm{M}_{\mathrm{O}_{3}}$ is the molecular weight of $\mathrm{O}_{3}$.

The average $\mathrm{O}_{3}$ uptake coefficient of the three cycles between the bypass and the flow tube per replicate was taken as the mean uptake coefficient for the experiment. We note that, for the low uptake rates observed in this work, gas phase diffusion was not limiting $\mathrm{O}_{3}$ loss, and the observed $\gamma$ was used without further correction. The uptake coefficient was measured as a function of the partial pressure of $\mathrm{O}_{3}$ in the gas phase. This allows for disentangling the contributions by the bulk aqueous phase reaction in the reacto-diffusive regime and the surface reaction, ${ }^{19,35}$ as described in more detail in the SI.

\section{RESULTS AND DISCUSSION}

Parts a and $\mathrm{b}$ of Figure 1 show $\mathrm{O} 1 \mathrm{~s}$ and $\mathrm{Br} 3 \mathrm{~d}$ photoelectron spectra, respectively, of $0.1 \mathrm{M} \mathrm{NaBr}$, and $0.1 \mathrm{M} \mathrm{TBA}-\mathrm{Br}$ aqueous solutions at photon energies of $900 \mathrm{eV}$ (2nd order light) and $450 \mathrm{eV}$, respectively. The $\mathrm{O} 1 \mathrm{~s}$ region in Figure $1 \mathrm{a}$ is fitted by two components that are assigned to gas phase water at ca. $541 \mathrm{eV}$ binding energy and liquid water at ca. $539 \mathrm{eV}$ binding energy. The chemical shift between $\mathrm{O} 1 \mathrm{~s}$ of liquid and gas phase water is different for $\mathrm{NaBr}$ and $\mathrm{TBA}-\mathrm{Br}$ solutions. This is also apparent in the valence spectra shown in Figure S1, which were used to align the binding energy scale with the $\mathrm{O}$ $1 b_{1}$ level of liquid water. This shift may be due to different surface potentials, and a similar effect was observed for different solutions in our previous work. ${ }^{33}$ The substantial photoemission intensity from gas phase water is related to the fact that the beam width of $60 \mu \mathrm{m}$ is larger than the liquid filament diameter of $25 \mu \mathrm{m}$, so that photoelectrons from excitations in the gas phase surrounding the liquid are also collected. The $\mathrm{Br} 3 \mathrm{~d}$ spectrum (Figure $1 \mathrm{~b}$ ) exhibits a double- peak structure due to spin-orbit splitting into $3 \mathrm{~d}_{5 / 2}$ and $3 \mathrm{~d}_{3 / 2}$. TBA-Br is expected to exhibit a surface excess of $\sim 3 \times 10^{14}$ molecule per $\mathrm{cm}^{2}$ at $0.1 \mathrm{M}^{13}$

It becomes already apparent from the spectra shown in Figure $1 \mathrm{~b}$ that the $\mathrm{Br} 3 \mathrm{~d}$ signal intensity, when referenced to the condensed $\mathrm{O}$ 1s signal, is substantially larger in TBA bromide solutions than in pure $\mathrm{NaBr}$ solutions. This is likely related to the positive surface excess of TBA and to either ion pairing or longer range electrostatic interaction with the positively charged TBA. This way more $\mathrm{Br}^{-}$ions are attracted into the liquid-vapor interface than in the neat $\mathrm{NaBr}$ solution with the same bromide bulk concentration. The surface activity of TBA, resulting in a carbon-rich layer at the interface, leads to attenuation of both $\mathrm{Br} 3 \mathrm{~d}$ and $\mathrm{O}$ 1s photoemission signals, which is directly apparent for the $\mathrm{O} 1 \mathrm{~s}$ signal of liquid water and will be quantitatively analyzed together with the $\mathrm{C} 1 \mathrm{~s}$ spectra further below. Note that the $y$-axis in terms of the count-rate is the same for the spectra within each panel; however, the intensity may also vary due to changes in the jet position from experiment to experiment. Therefore, it is not clear whether the different gas phase signals in Figure 1a indicate an effect of TBA on the evaporation of $\mathrm{H}_{2} \mathrm{O}$ from the liquid.

The same $\mathrm{O}$ 1s (Figure 1c) and $\mathrm{Br} 3 \mathrm{~d}$ (Figure 1d) spectra were taken in the presence of $\mathrm{O}_{3} / \mathrm{O}_{2}$ to probe the bromide ozonide (intermediate in the reaction to hypobromite) at the same information depth. The relatively larger contribution of gas phase water compared to the experiments without gas dosing is due to the presence of gas phase oxygen $(0.25 \mathrm{mbar})$, which leads to a higher local water vapor concentration around the liquid filament due to diffusion limitation. The higher pressure also leads to more attenuation of the $\mathrm{O} 1 \mathrm{~s}$ signal from condensed phase water. Note that the $\mathrm{O}$ 1s peak related to gas phase oxygen is at a binding energy about $7 \mathrm{eV}$ higher than that of gas phase water (see Figure S2), thus outside the binding energy range shown in Figure 1c.

In Figure 1d, both $\mathrm{Br}$ species show two spin orbit split doublets, which are assigned to $\mathrm{Br}^{-}$and the $[\mathrm{Br} \cdot \mathrm{OOO}]^{-}$ 

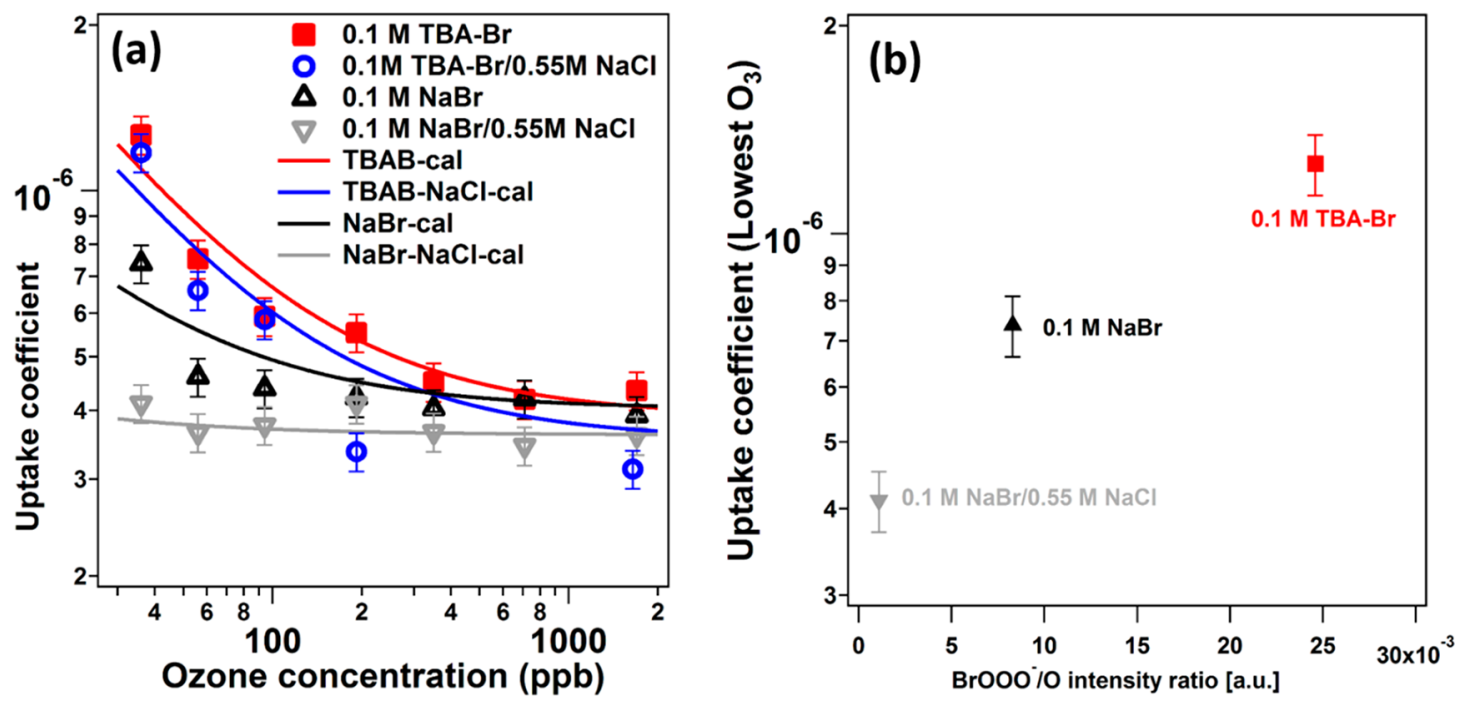

Figure 2. (a)nMeasured and parametrized uptake coefficients of $\mathrm{O}_{3}$ as a function of gas phase $\mathrm{O}_{3}$ concentration for $0.1 \mathrm{M} \mathrm{NaBr}$ (black), $0.1 \mathrm{M}$ $\mathrm{NaBr} / 0.55 \mathrm{M} \mathrm{NaCl}$ (gray), 0.1 M TBA-Br (red), and 0.1 M TBA-Br/0.55 M NaCl (dark-blue) in the aqueous solutions. (b) Uptake coefficient of $\mathrm{O}_{3}$ at $36 \mathrm{ppb}$ compared with the measured $[\mathrm{Br} \cdot \mathrm{OOO}]^{-} / \mathrm{O}$ intensity ratio for three different aqueous solutions.

intermediate. The doublet assigned to the $[\mathrm{Br} \cdot \mathrm{OOO}]^{-}$ intermediate is positively shifted by $0.7 \mathrm{eV}$ with respect to $\mathrm{Br}^{-}$, in line with the previous study by Artiglia et al., ${ }^{20}$ which also provides a more detailed explanation for the fitting procedure. In support of the presence of this second $\mathrm{Br}$ species, we added the spectra of Figure 1d to Figure S2, using a fit with just one bromine species, bromide, but using width and spinorbit split constrained by the measurement in absence of $\mathrm{O}_{3}$. The residuals clearly show the need to add this second species to properly fit the spectra. In a vacuum, the $\mathrm{Br} 3 \mathrm{~d}$ signal intensity was clearly larger in TBA bromide containing solutions than that in pure $\mathrm{NaBr}$ solutions. In the presence of $\mathrm{O}_{2} / \mathrm{O}_{3}$, the ratio between the two is even larger. Note that even though the ratio of the signal intensity contributed by the $[\mathrm{Br} \cdot \mathrm{OOO}]^{-}$intermediate to that contributed by the $\mathrm{Br}^{-}$ species is rather similar in the presence and absence of TBA$\mathrm{Br}$, at $0.21 \pm 0.04$ and $0.15 \pm 0.03$, respectively, the concentration and stability of the intermediate are clearly different in the presence of TBA, as discussed in detail in the second part.

In parallel, we performed kinetic experiments of the reactivity of $\mathrm{O}_{3}$ with the same solutions. The uptake kinetics is expressed by the uptake coefficient, representing the rate of $\mathrm{O}_{3}$ loss from the gas phase normalized to the gas-kinetic collision rate, defined in eq 2 . Figure $2 \mathrm{a}$ shows the measured and parametrized uptake coefficients of $\mathrm{O}_{3}$ as a function of gas phase $\mathrm{O}_{3}$ concentration for aqueous solutions containing 0.1 M NaBr (black), $0.1 \mathrm{M} \mathrm{NaBr} / 0.55 \mathrm{M} \mathrm{NaCl}$ (gray), $0.1 \mathrm{M}$ TBA-Br (red), and 0.1 M TBA-Br/0.55 M NaCl (dark-blue), which directly demonstrate the obvious enhancement of reactivity for the TBA containing solutions at low $\mathrm{O}_{3}$ mixing ratios. Lines are fits with a kinetic model consisting of a combination of a Langmuir-Hinshelwood type surface reaction and a reaction-diffusion mechanism in the bulk phase based on our previous study ${ }^{20}$ and as described in the Supporting Information, Section VIII. At high ozone concentrations (above $200 \mathrm{ppb}$ ), the uptake coefficients are constant, whereas the uptake coefficients are increasing toward the lower atmospherically relevant ozone mixing ratios (between 100 and $30 \mathrm{ppb}$ ). In previous studies, ${ }^{19,20}$ this behavior has been attributed to a surface reaction dominating at a low ozone concentration. It results from the fact that the surface coverage of $\mathrm{O}_{3}$ is saturating at a higher concentration, which leads to the surface reaction rate saturating with a higher ozone concentration, as described by eq S21 in the SI. In contrast, the bulk phase concentration of $\mathrm{O}_{3}$ scales linearly with the gas phase partial pressure (Henry's law) in the relevant concentration range, which leads to the bulk reaction rate remaining independent of the ozone concentration in the gas phase (eq S22 in the SI). In a recent study with a similar reactor of comparable geometry, it has been suggested that liquid phase diffusion may limit the uptake coefficient. ${ }^{49}$ As also explained in the SI, the bulk diffusion limitation of bromide can be excluded under the present conditions. The measured ozone uptake coefficients in the absence of TBA are consistent with previous studies from our group ${ }^{20}$ and the work by Oldridge and Abbatt. ${ }^{19}$ The small difference between the pure $\mathrm{NaBr}$ and the mixed $\mathrm{NaBr} / \mathrm{NaCl}$ solutions at a high ozone concentration is explained by the $10 \%$ lower solubility of $\mathrm{O}_{3}$ due to salting out by the $0.55 \mathrm{M} \mathrm{NaCl}$ and the small difference in diffusivity caused by a small change in viscosity. Both are included in the parametrization for the uptake coefficient (see the Supporting Information, section VIII). In the presence of TBA, the ozone uptake coefficient is higher than those on the pure $\mathrm{NaBr}$ and $\mathrm{NaBr} / \mathrm{NaCl}$ mixed solutions at low ozone concentrations, whereas they tend to be similar to the systems without TBA at higher ozone concentrations, indicating that the surface reaction contribution is more strongly affected by the presence of TBA than the bulk reaction. The rather small difference between ozone uptake in solutions with and without TBA at a high ozone concentration could be explained by $11.5 \%$ larger viscosity and $1.5 \%$ larger solubility of $\mathrm{O}_{3}$ in TBA-Br solutions compared with those of pure $\mathrm{NaBr}$. In the presence of TBA, the effect of $0.55 \mathrm{M} \mathrm{NaCl}$ is also seen, especially at a high ozone concentration, which is due to both the higher viscosity (11.5\% higher) and the lower solubility of $\mathrm{O}_{3}(7.8 \%$ lower) compared with those of pure $\mathrm{NaBr}$. For the bulk reaction, the parametrization for the uptake coefficient is based solely on known parameters (solubility, rate coefficient, diffusivity) without any additional adjustable 
parameters. For the loss rate on the surface, as described in the Supporting Information (section VIII), the essential parameters are the equilibrium constant for the formation of the intermediate ( $K_{\text {Lang }}$ in eq S21), the maximum surface coverage of the intermediate $\left(N_{\max }\right)$, and the first-order decay rate coefficient $\left(k_{\mathrm{s}}\right)$ for the formation of the product $\mathrm{BrO}^{-}$. Whereas the value for $K_{\text {Lang }}$ was taken from Artiglia et al., ${ }^{20}$ which was also consistent with Oldridge and Abbatt, ${ }^{19}$ the maximum surface coverage was constrained by the XPS data (as described further below), and the rate coefficient was the only adjustable parameter used to fit the data, leading to very good fits for each solution, as shown in Figure 2 a.

The strikingly parallel behavior of the enhancement of the surface contribution of the uptake coefficient in the presence of TBA and that of the increased presence of both bromide and the reaction intermediate, as determined by XPS, supports the hypothesis that the positively charged ammonium group in TBA helps to attract $\mathrm{Br}^{-}$ions to the interface and establishes an enhanced surface concentration of the $[\mathrm{Br} \cdot \mathrm{OOO}]^{-}$ intermediate limiting the reaction rate. Sobyra et al. ${ }^{42}$ studied the production of $\mathrm{Br}_{2}$ from the reaction of $\mathrm{N}_{2} \mathrm{O}_{5}$ with $\mathrm{Br}^{-}$in TBA-Br solutions. They found a reduction of $\mathrm{Br}_{2}$ formation in the presence of TBA and attributed that to ion-pairing of $\mathrm{TBA}^{+}$ with $\mathrm{Br}_{3}{ }^{-}$at the liquid-vapor interface. Since our experiments are not sensitive to the products, neither in the kinetics nor in the spectroscopy experiment, we cannot assess the fate of $\mathrm{BrO}^{-}$in our case. Similarly, a possibly enhanced loss rate of $\mathrm{N}_{2} \mathrm{O}_{5}$ to a bromide enriched interface would have remained undetected in the experiments by Sobyra et al. To make the rate-limiting role of the $[\mathrm{Br} \cdot \mathrm{OOO}]^{-}$intermediate directly apparent, Figure $2 \mathrm{~b}$ shows the linear correlation between the uptake coefficient of $\mathrm{O}_{3}$ at $36 \mathrm{ppb}$ and the measured ratio of the $\mathrm{Br} 3 \mathrm{~d}$ photoemission intensity from the $[\mathrm{Br} \cdot \mathrm{OOO}]^{-}$ intermediate to the $\mathrm{O} 1 \mathrm{~s}$ intensity of liquid water for three different aqueous solutions. Note that it was not possible to reliably fit the $\mathrm{Br} 3 \mathrm{~d}$ spectrum in terms of the intermediate in the case of the mixed solution of $0.1 \mathrm{M}$ TBA-Br and $0.55 \mathrm{M}$ $\mathrm{NaCl}$. Note that, in the XPS experiment, we cannot quantify the local $\mathrm{O}_{3}$ pressure near the liquid surface but assume that it is higher than in the kinetic experiments. This leads to saturating surface concentrations of the intermediate. In the kinetic experiments, at such a high concentration, the bulk reaction is dominating the loss of $\mathrm{O}_{3}$, even though the loss rate at the surface remains the same as at the lowest partial pressures of $\mathrm{O}_{3}$. As already discussed in Artiglia et al., ${ }^{34}$ the $\mathrm{BrO}^{-}$product produced in the bulk or at the surface is not detected by XPS due to fast diffusional exchange in the liquid phase beyond the probe depth of XPS.

In an attempt to link the enhanced reactivity more quantitatively to the local interfacial concentration of bromide, we developed an attenuation model to account for the attenuation of photoelectrons by the "layer" formed by the aliphatic carbon chains of the TBA surfactant that are residing at the interface (Figure 3). This model is then constrained by the available photoemission data. The attenuation model used in the present work is following the one developed by Lee et al. $^{33}$ Its setup, depicted in Figure 3, assumes that the interfacial region contains TBA, the concentration of which is constrained by surface tension measurements. In more detail, we assume that the cationic $\mathrm{N}$ and its surrounding $\mathrm{C}$ atoms reside on the bulk side of the interface, with three of the remaining aliphatic chains above it, within a layer of thickness $d_{1}$, and one aliphatic chain pointing toward the bulk, extending to a depth $d_{2}$,

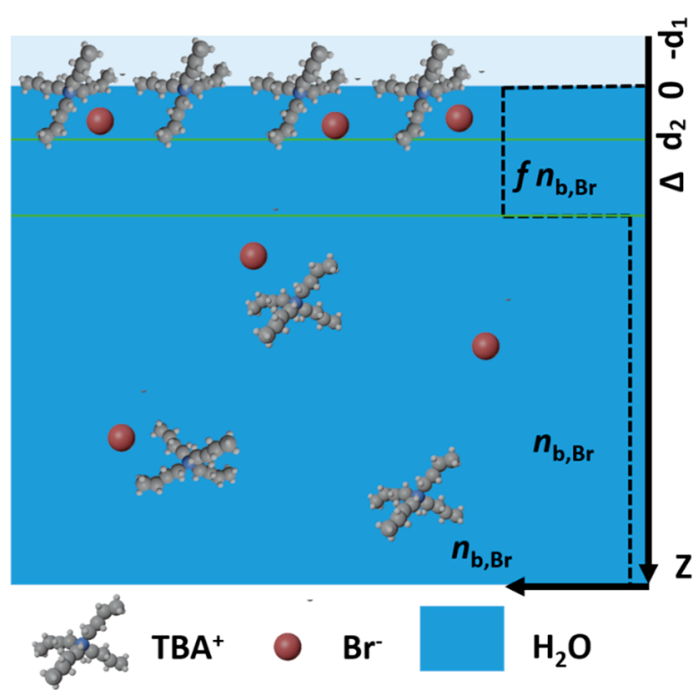

Figure 3. Scheme of the TBA covered interface used for the attenuation model. The reference level 0 for the depth scale (z) denotes the position where the water density drops to zero and is put just above the N-group of TBA, such that the aliphatic carbons of three of the butyl chains reside at $-d_{1}<z<0$ (on the vacuum side). The aliphatic carbons of the fourth chain are within $z<d_{2}$. The layer $0<z<\Delta$ is representing the layer in which the concentration of bromide is deviating from its bulk value, $n_{\mathrm{b}, \mathrm{Br}}$, by the factor $f$. Red, blue, and dark and light gray spheres denote bromide, nitrogen, carbon, and hydrogen atoms, respectively.

inspired by molecular dynamics simulations presented by Winter et al. ${ }^{39}$ for TBA iodide. We further consider a region of thickness $\Delta$ within which the bromide concentration differs from that in the bulk aqueous phase, as in Lee et al. ${ }^{33}$ Its thickness $\Delta$ is independent of whether TBA is present or not. The details of the attenuation model and the derivation of the equations describing the photoemission signals are provided in the Supporting Information (Section VI). These equations fully account for the exponentially decaying contribution of photoelectrons from atoms with depth below the surface. For each element, these contributions are integrated over the density profiles as described above. Since the structure of the bromide ozonide intermediate at the TBA covered interface is not clear and its coverage on the surface remains small, we refrain from applying the model in any way to the $\mathrm{Br} 3 \mathrm{~d}$ photoemission intensities of the intermediate.

We first used the $C 1$ s photoemission data shown in Figure S4 to constrain the thickness, $d_{1}$, of the top layer $\left(-d_{1}<z<0\right)$, which is the basis for the attenuation of all photoemission signals originating from the bulk. As shown in Figure $4 a$, the aliphatic group $C$ 1s photoemission intensity for the TBA-Br solutions measured at $660 \mathrm{eV}$ photon energy as a function of the concentration from 0.01 to $0.2 \mathrm{M}$ (see individual spectra in the Supporting Information, Section IV and Figure S4), which essentially tracks the evolution of the surface excess as derived from surface tension data (Supporting Information, Section VII and Figures S6 and S7). ${ }^{13}$

Meanwhile, the correlation between C 1s photoemission intensity and the surface excess has been demonstrated for many surface active organic species. ${ }^{32,33,50-53}$ The surface excess formed the basis for the retrieval of the effective thickness of the layer formed by the aliphatic carbons from the calculated C 1s signal fitted to the data (eq S6). The purpose was to replace detailed electron scattering calculations by 

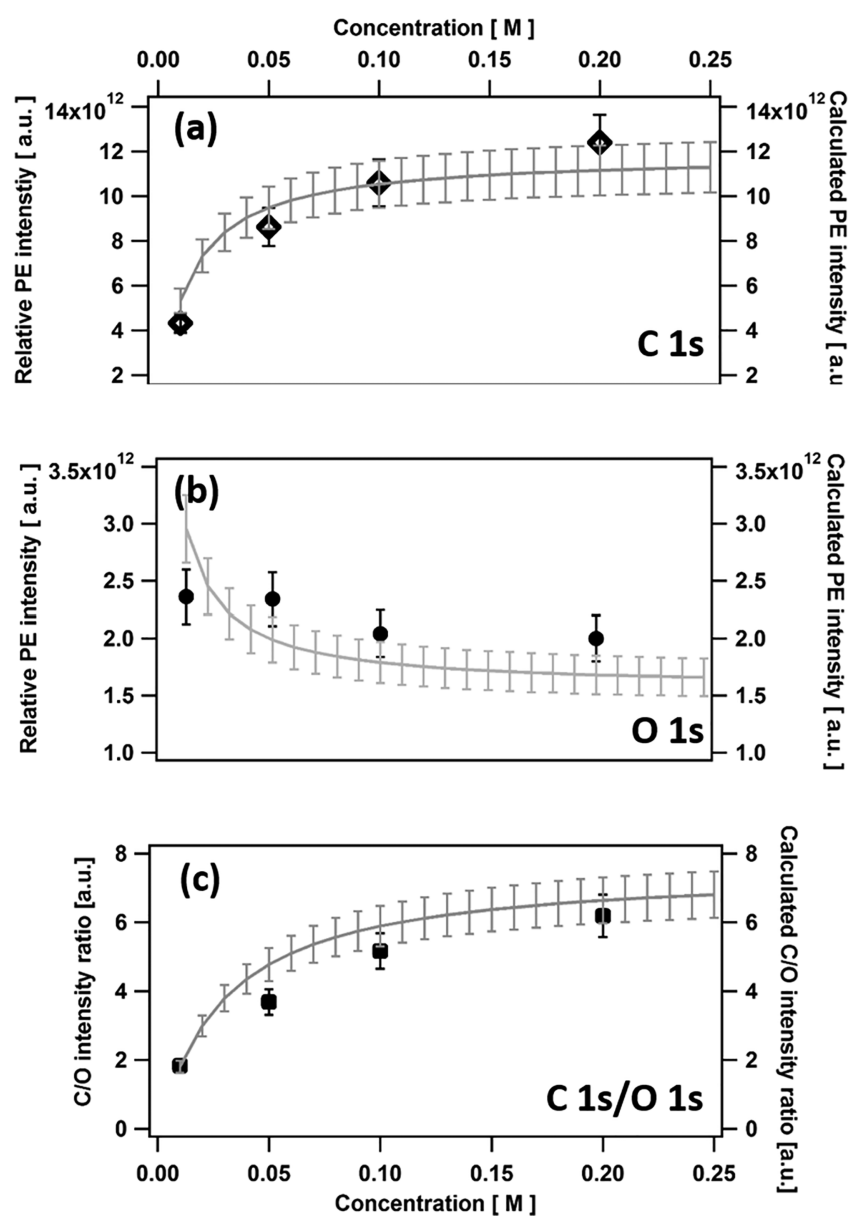

Figure 4. (a) Normalized methyl carbon $C 1$ s and (b) liquid water $O$ $1 \mathrm{~s}$ photoemission intensity as a function of TBA-Br concentration for four different $\mathrm{TBA}-\mathrm{Br}$ concentrations, measured at photon energies of 660 and $900 \mathrm{eV}$, respectively. (c) Normalized C/O intensity ratio as a function of TBA-Br concentration from the data in (a) and (b). Normalization as described in the text. Symbols present the experimental data, and the lines are the calculated quantities returned by the attenuation model described in the text.

assuming a homogeneous layer consisting of liquid butane, for which we could approximate the inelastic mean free path by that of liquid water (see the Supporting Information, Section VII). In Figure $4 b$, we show the concomitant decrease of the condensed phase $\mathrm{O} 1 \mathrm{~s}$ signal of $\mathrm{H}_{2} \mathrm{O}$. We note that the decrease is less pronounced than expected from the attenuation of photoelectrons by the increasing effective thickness of the aliphatic carbon layer as calculated by the model (eq S7), possibly because water molecules hydrating the central cation are filling a larger fraction of the carbon chain than assumed in the model. The ratio of the two signals is shown in Figure $4 c$ exhibiting the typical feature for surfactant behavior. ${ }^{29,51}$ Note that the calculated lines were scaled with a factor, since the absolute detection efficiency is not known. For the ratio in Figure 4c, this provides the calibration factor for the $\mathrm{C} 1 \mathrm{~s}$ to $\mathrm{O} 1 \mathrm{~s}$ photoemission intensity ratio, $A / B$, in eq $\mathrm{S} 10$. The calculated effective layer thickness, $d_{1}$, as a function of the TBA bulk concentration led to good agreement with the data. This thickness was then used for the quantitative analysis of the bromine signals further below. Apart from providing surface composition data, the ratio of photoemission intensities contributed by the aliphatic carbons to that by the amine coupled carbons contains information about the orientation of the surfactants. ${ }^{31,51,54}$ For simple monocarboxylic acids, the headgroup is solvated while the aliphatic chains are residing above the surface. Therefore, photoelectrons from the aliphatic carbons are less attenuated than those from the headgroup carbon, leading to enhanced photoemission signal intensity ratios. However, in the case of TBA, this effect is rather weak (Figure S5), because only one of the butyl chains is pointing upward, while two are lying flat on the surface and one is pointing into the solution, ${ }^{38}$ as schematically depicted in Figure 3. In the bulk phase, the complete hydration of TBA with around 20 water molecules as well as counterions between the hydrocarbon arms of TBA was derived from molecular dynamics simulations. ${ }^{55}$ No aggregation was apparent. At the surface, our results of the $\mathrm{C} / \mathrm{O}$ intensity ratio indicate that at least part of the aliphatic carbon chains is not hydrated. This might be part of the driving force for residing at the surface. In addition, the large polarizability and size of TBA ions also contribute to their surface propensity. ${ }^{38}$

Figure 5 shows the photoemission spectra of the $\mathrm{Br} 3 \mathrm{~d}$ (a), $\mathrm{O} 1 \mathrm{~s}(\mathrm{~b}), \mathrm{C} 1 \mathrm{~s}(\mathrm{c}), \mathrm{N} 1 \mathrm{~s}(\mathrm{~d})$, and $\mathrm{Cl} 2 \mathrm{p}$ (e) core level regions for $0.1 \mathrm{M}$ TBA-Br (red), $0.1 \mathrm{M} \mathrm{TBA}-\mathrm{Br} / 0.55 \mathrm{M} \mathrm{NaCl}$ (dark blue), 0.1 M TBA-Br/0.1 M NaBr (pink), and 0.1 M TBA-Br/ $0.1 \mathrm{M} \mathrm{NaBr} / 0.55 \mathrm{M} \mathrm{NaCl}$ (light blue) aqueous solutions. We used photon energies of $229 \mathrm{eV}$ for $\mathrm{Br} 3 \mathrm{~d}, 696 \mathrm{eV}$ for $\mathrm{O} 1 \mathrm{~s}$ (2nd order light component of the $348 \mathrm{eV}$ photon energy adjusted at the monochromator), $448 \mathrm{eV}$ for $\mathrm{C} 1 \mathrm{~s}$, and $560 \mathrm{eV}$ for $\mathrm{N} 1 \mathrm{~s}$ to obtain the same kinetic energy of around $155 \mathrm{eV}$. Thus, the data in Figure 5 was obtained at a smaller kinetic energy than those in Figure 1 to achieve a higher surface sensitivity. We measured the $[\mathrm{Br} \cdot \mathrm{OOO}]^{-}$intermediate at a kinetic energy of $370 \mathrm{eV}$ to have better signal-to-noise ratio for quantitative analysis and for comparison with our previous work. $^{20}$ The shapes of $\mathrm{O} 1 \mathrm{~s}$ and $\mathrm{Br} 3 \mathrm{~d}$ have already been discussed above in relation to Figure 1. The lower kinetic energy leads to a higher ratio of gas phase to condensed phase water signal for the $\mathrm{O} 1 \mathrm{~s}$ level. $\mathrm{C}$ 1s (Figure 5c) exhibits, as also seen in Figure S4, two features representing aliphatic chain carbon $\left(-\mathrm{C}_{3} \mathrm{H}_{7}\right)$ and the ammonium coupled carbon $\left(-\mathrm{CH}_{2}-\right.$ $\mathrm{N}$ ) at binding energies of 290.6 and $291.9 \mathrm{eV}$, respectively. The $\mathrm{N}$ 1s spectrum (Figure $5 \mathrm{~d}$ ) shows a single peak at a binding energy of $408.0 \mathrm{eV}$.

The first step toward the quantification of the surface composition is to consider the signal intensity ratioed to that of $\mathrm{O} 1 \mathrm{~s}$, since then several uncertainty factors, such as the transmission function of the analyzer, or a variable jet position are canceling out. Table 1 summarizes the ratios of $\mathrm{Br} 3 \mathrm{~d}, \mathrm{C} 1 \mathrm{~s}$, $\mathrm{N} \mathrm{1s}$, and $\mathrm{Cl} 2 \mathrm{p}$ intensities to that of $\mathrm{O} 1 \mathrm{~s}$. Each signal intensity has also been normalized to the total photoionization cross section and photon flux. Since for the O 1s measurement we used second order light, for which we have not quantified the photon flux precisely, these ratios are not absolute elemental ratios but should be considered relative with respect to the different solutions. For the $\mathrm{C} 1 \mathrm{~s}$ to $\mathrm{O} 1 \mathrm{~s}$ signal intensity ratio, we note that, on the basis of the calibration factor obtained from fitting the TBA concentration dependent data (Figure 4), we can use the TBA-Br solution with its known surface excess to derive the TBA surface excess of the other solutions, as $C 1$ s signal intensity ratios scale linearly with the surface excess for different solutions. ${ }^{33,51,53}$

Qualitatively, and in extension to the data presented in Figure 1, the $\mathrm{Br}$ spectra in Figure 5 and $\mathrm{Br} / \mathrm{O}$ ratios presented in the first column of Table 1 show the dramatic enhancement 

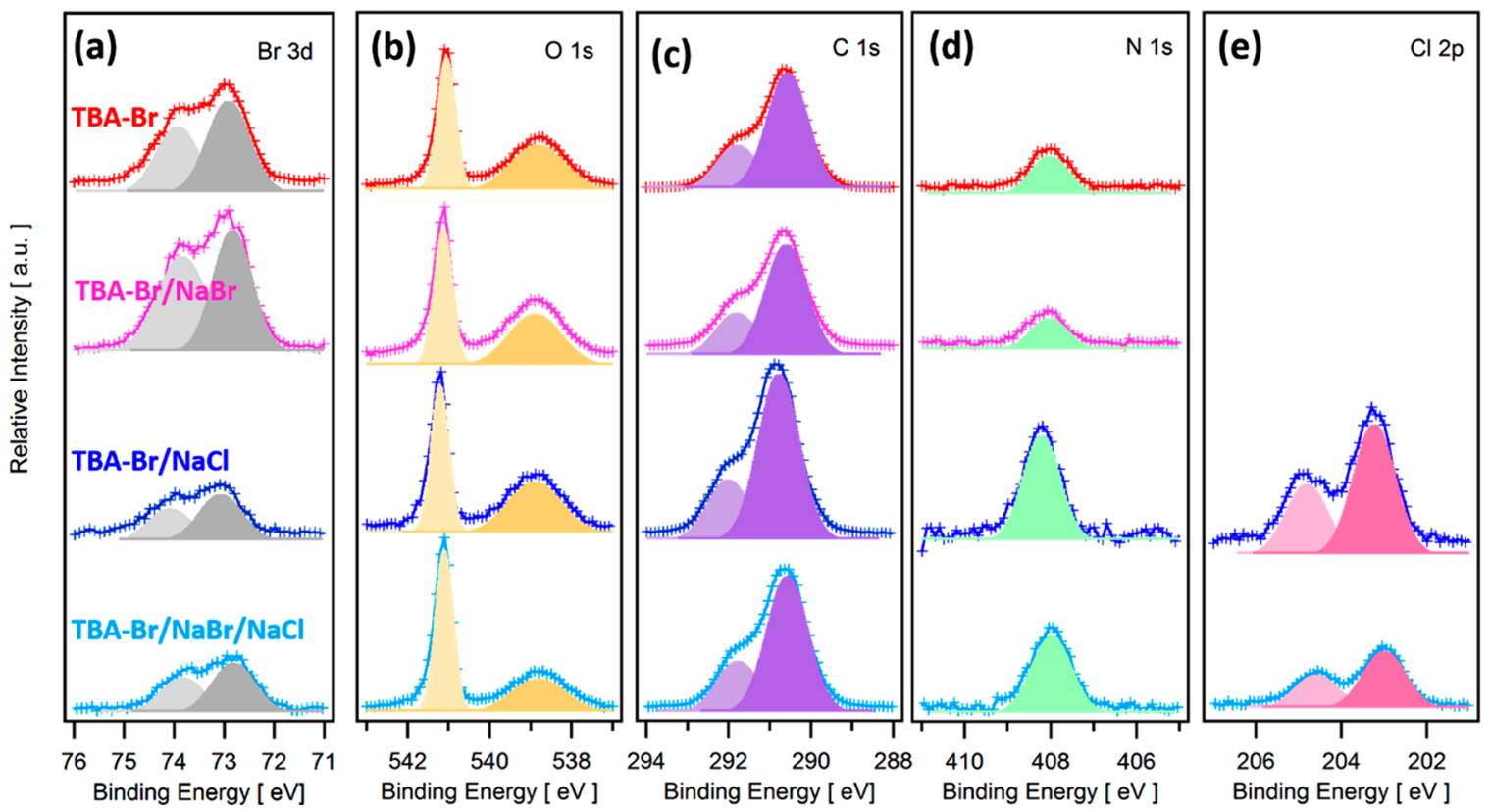

Figure 5. (a) $\mathrm{Br} 3 \mathrm{~d},(\mathrm{~b}) \mathrm{O} 1 \mathrm{~s},(\mathrm{c}) \mathrm{C} 1 \mathrm{~s},(\mathrm{~d}) \mathrm{N} 1 \mathrm{~s}$, and (e) $\mathrm{Cl} 2 \mathrm{p}$ photoemission spectra of aqueous solutions taken at a kinetic energy of $155 \mathrm{eV}$ for $0.1 \mathrm{M}$ TBA-Br (red), $0.1 \mathrm{M}$ TBA-Br/0.55 M NaCl (dark blue), $0.1 \mathrm{M}$ TBA-Br/0.1 M NaBr (pink), and 0.1 M TBA-Br/0.1 M NaBr/0.55 M NaCl (light blue), normalized to the the number of sweeps. Lines with symbols represent the measured data, and the shaded areas represent the fitted contributions of the corresponding core levels.

of the $\mathrm{Br}$ signal in the presence of TBA, as well as a partial suppression of this enhancement by $0.5 \mathrm{M} \mathrm{NaCl}$. In addition, salting out of bromide to the surface by $\mathrm{NaCl}$ is apparent in absence of TBA. Furthermore, the $\mathrm{C} 1 \mathrm{~s}$ and $\mathrm{N}$ 1s data in Figure 5 and Table 1 indicate a salting out of TBA in the presence of $\mathrm{NaCl}$, meaning that more TBA is pushed to the interface in the presence of $\mathrm{NaCl}$. These features will be discussed one by one below.

For a quantitative interpretation of the $\mathrm{Br}$ data and its link with the reactivity discussed above, we have used the observed $\mathrm{Br} / \mathrm{O}$ signal intensity ratios to obtain the interfacial concentration of bromide, $n_{\mathrm{Br}, \Delta}$, within the layer of thickness $\Delta$ (see the conceptual model of the interface, Figure 3$)$. This is described by the factor, $f$, representing the enhancement $(f>$ 1) or depletion $(f<1)$ in comparison to the bromide concentration in the bulk, $n_{\mathrm{Br}, \mathrm{b}}$ (Figure 3), $n_{\mathrm{Br}, \Delta}=f n_{\mathrm{Br}, \mathrm{b}}$. The results are listed in Table 1 both in terms of $n_{\mathrm{Br}, \Delta}$ in units of $\mathrm{M}$ and as effective surface coverage, $n_{\mathrm{Br}, \Delta} \Delta$, in units of molecules $\mathrm{cm}^{-2}$. For the pure $\mathrm{NaBr}$ solution, we used the same approach as in Lee et al. ${ }^{33}$ to link the $\mathrm{Br} / \mathrm{O}$ signal intensity ratio to the surface excess (Supporting Information, Section VI, eqs S11 and S14). Note that the choice of $\Delta=1 \mathrm{~nm}$ is somewhat arbitrary. But, this depth seems reasonable to represent the interfacial region in view of a number of molecular dynamics simulations on such systems. ${ }^{34,38,39,42}$ We note that all other surface concentrations discussed below are depending on this choice, leading to systematic uncertainty. $f_{0}=0.5$ (for pure 0.1 $\mathrm{M} \mathrm{NaBr}$ ) was obtained from the surface excess of $-3 \times 10^{12}$ molecules per $\mathrm{cm}^{-2}$ (eq S11), which is consistent with surface tension data at $0.1 \mathrm{M}$ concentration. ${ }^{56}$ This means that, within this surface layer, the average concentration of bromide is about $50 \%$ of its bulk value, thus $0.05 \mathrm{M}$ or an effective surface concentration of $3 \times 10^{12}$ ions $\mathrm{cm}^{-2}$ (see Table 1 ). The depleted character at the surface of halide solutions is thus in agreement with surface tension data and also other liquid jet photoemission studies and the most recent molecular dynamics simulations with revised force fields. ${ }^{34,57,58}$

In the presence of TBA, the deviation of $f$ from $f_{0}$ is described as a linear function of the surface coverage of TBA, with the parameter $a$ describing the maximum enhancement at saturating coverage (SI, eq S13). The parameter $f$ was obtained from eq S13 and using the calibration factor for the $\mathrm{Br} / \mathrm{O}$ signal intensity ratio determined from the pure $\mathrm{NaBr}$ solution (Supporting Information, eq S15). Using $f$, we obtained the interfacial bromide concentration, which is enhanced by a factor of 20 in comparison to that of the pure $\mathrm{NaBr}$ solution. This takes into account the attenuation by TBA on the surface, which leads nearly to a doubling of the relative enhancement in comparison to that apparent from the $\mathrm{Br} 3 \mathrm{~d}$ signal. This enhancement is likely due to electrostatic interactions between bromide and the positively charged TBA, including the formation of ion pairs. Such interactions have been found earlier for other surfactant systems ${ }^{30}$ and specifically also for solutions containing TBA iodide. ${ }^{38,39,59-61}$ Using He backscattering, Zhao et al. ${ }^{62}$ determined that bromide is distributed within a width of around one nanometer at the interface for tetrahexylammonium (THA) bromide in glycerol as a solvent. Note that this is compatible with our choice of $\Delta$ used to calculate local concentrations. In turn, the probe depth of our experiment, typically defined as three times the mean escape depth (around $1 \mathrm{~nm}$, see the Supporting Information, Section VI for details), is larger. Nevertheless, while $95 \%$ of the signal originates from around $3 \mathrm{~nm}$, still about $80 \%$ comes from the first nanometer. However, all of this is embodied in the integrations to calculate the signal intensities on the basis of the attenuation model. The TBA surface coverage given in the table for TBA-Br is the same as that used for the fits in Figure 4 and is based on surface tension measurements at $0.1 \mathrm{M} .^{13}$ In turn, the effective surface coverage of bromide is a factor of 5 lower, meaning that not all TBA ions have formed pairs with bromide. Bhowmik et al. ${ }^{55}$ suggested that, in solutions with 


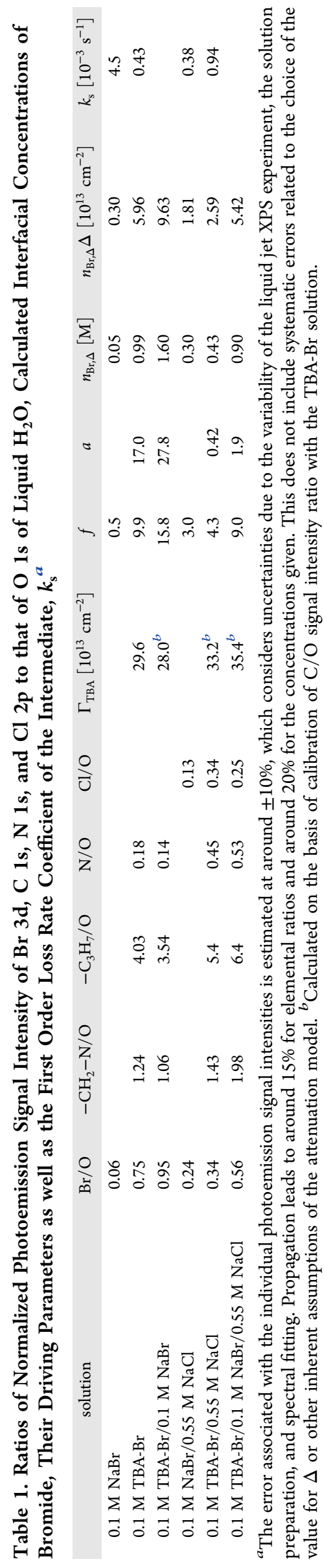

higher bulk concentrations, bromide resides in the spaces between the butyl chains in fully hydrated form. Therefore, even if at the interface part of these chains are avoiding the aqueous phase, there would be sufficient room for equimolar amounts of bromide to approach the cations. Also, on the basis of the $\mathrm{C} / \mathrm{O}$ and $\mathrm{Br} / \mathrm{O}$ ratios and the concentrations derived, the substantial amounts of water ${ }^{52,63}$ (in terms of mole fraction) at the interface should not be a limiting factor for bromide approaching the interfacial region. The question remains whether $\mathrm{OH}^{-}$is competing with bromide or whether neutral TBAOH (TBA hydroxide) is stabilized at the interface. In the presence of additional $0.1 \mathrm{M} \mathrm{NaBr}$, thus doubling the amount of bromide in the bulk, the interfacial bromide concentration increases by $60 \%$, thus less than a factor of 2 . This nonlinear response to additional bromide is also consistent with the presence of such competing processes. Note that, in the calculation of the surface concentrations from recorded XPS intensities, the contribution by the increasing bulk concentration is taken into account (Supporting Information, eq S12), although it remains very small due to the predominant contribution of bromide at the interface. The surface excess of TBA, calculated by linear scaling on the basis of the $\mathrm{C} / \mathrm{O}$ ratios and using the $0.1 \mathrm{M}$ TBA-Br solution as reference, did not change significantly in the presence of additional $0.1 \mathrm{M} \mathrm{NaBr}$ added to TBA-Br (the calculated value is actually below that of TBA-Br but is considered remaining within the error bounds of the 0.1 M TBA-Br solution).

When $0.55 \mathrm{M} \mathrm{NaCl}$ (representing roughly ocean water chloride concentration) is present together with $0.1 \mathrm{M} \mathrm{NaBr}$, but in absence of TBA, the interfacial concentration of $\mathrm{Br}^{-}$ calculated from the $\mathrm{Br} / \mathrm{O}$ photoemission intensity ratio is 0.30 $\mathrm{M}$, which is a factor of 6 higher than in the case of the pure $\mathrm{NaBr}$ solution. This apparent salting out of bromide, or, in other words, enhanced $\mathrm{Br} / \mathrm{Cl}$ ratio at the interface due to the higher polarizability of bromide versus that of chloride, has been reported and discussed before. ${ }^{64}$ Exploring it further was not the scope of the present study.

In the presence of both $\mathrm{NaCl}$ and TBA bromide, several effects come together. Apart from the higher surface propensity of bromide in the presence of chloride, TBA experiences salting out, too, and chloride may compete with bromide for ion-pairing with TBA at the interface. Taking the calibration for the aliphatic $\mathrm{C} 1 \mathrm{~s}$ to water $\mathrm{O} 1 \mathrm{~s}$ photoemission ratio for the TBA-Br solution, the $20 \%$ increase of the $\mathrm{C} / \mathrm{O}$ ratio leads to a surface excess of $3.3 \times 10^{14} \mathrm{~cm}^{-2}$ of TBA in the presence of $0.55 \mathrm{M} \mathrm{NaCl}$, thus an increase by about $10 \%$ compared to the $0.1 \mathrm{M}$ TBA-Br solution. Salting effects of organics in the presence of inorganic electrolytes, with salting out being the more common case, are a well-described phenomenon, but predictive tools remain poorly constrained. ${ }^{65,66}$ Salting out has been substantiated also by XPS for butanol in the presence of iodide $^{67}$ or by scattering for THA bromide in the presence of $0.3 \mathrm{M} \mathrm{NaBr}^{62}$ In the latter case, though in glycerol, a widening of the depth profile of THA has been observed, possibly beyond the thickness of a monolayer. In the present work, the photoemission signals of the carbons directly attached at the amine nitrogen changed in accordance with the aliphatic carbons, meaning that no substantial change in average orientation is apparent. On the contrary, the $\mathrm{N} 1 \mathrm{~s}$ to $\mathrm{O} 1 \mathrm{~s}$ signal intensity ratio changed by more than a factor of 2 . It could indicate that the amine group of a fraction of the TBA ions has moved toward the vacuum side of the interface, which would also point toward a more complex structure than the 
simple ideal monolayer assumed in our attenuation model. More detailed kinetic energy dependent XPS experiments would be required to explore this further. The analysis of the $\mathrm{Br} / \mathrm{O}$ ratios and the estimation of the interfacial bromide concentration within $0<z<\Delta$ would not be affected by such a potentially thicker overlayer at $z<0$, as $\mathrm{Br}$ and $\mathrm{O}$ photoemission signals would experience the same degree of attenuation.

While the amount of TBA at the surface increases in the presence of chloride, a 3-fold decrease of the $\mathrm{Br} / \mathrm{O}$ signal intensity ratio was observed, corresponding to a decrease of the interfacial concentration within $0<z<\Delta$ by about $60 \%$ in comparison to that of the $0.1 \mathrm{M}$ TBA-Br solution in the absence of $\mathrm{NaCl}$. The decrease in the bromide concentration can be rationalized by the competition between $\mathrm{Cl}^{-}$and $\mathrm{Br}^{-}$ for ion-pairing with TBA. The association constant of TBA with $\mathrm{Br}^{-}$is about 1 order of magnitude higher than that with $\mathrm{Cl}^{-}$. ${ }^{68}$ This explains why in spite of a factor of 5 excess of $\mathrm{Cl}^{-}$ still $40 \%$ of the $\mathrm{Br}^{-}$concentration determined for the case of $0.1 \mathrm{M}$ TBA-Br remains at the interface. A similar difference in association constants for $\mathrm{Br}^{-}$and $\mathrm{Cl}^{-}$exists with $\mathrm{NH}_{4}{ }^{+69}$ For alkylammonium cations, the association constants decrease with anion size and polarizability, e.g., for the pairs of TBA-I and $\mathrm{TBA}-\mathrm{ClO}_{4}{ }^{70}$ or for TBA-I and TBA-Br. ${ }^{71}$ For the latter pair, Winter et al. ${ }^{39}$ found only a small decrease of the iodine photoemission signal when adding $\mathrm{NaBr}$ to TBA-I, comparable to our observations. When looking at the chlorine signal in our experiments, the $\mathrm{Cl} / \mathrm{O}$ ratio (see Table 1 ) increased by nearly a factor of 3 from the $0.1 \mathrm{M} \mathrm{NaBr} / 0.55 \mathrm{M} \mathrm{NaCl}$ solution to that with $0.1 \mathrm{M}$ TBA-Br/ $0.55 \mathrm{M} \mathrm{NaCl}$. In turn, when adding another $0.1 \mathrm{M} \mathrm{NaBr}$, the $\mathrm{Cl} / \mathrm{O}$ ratio again decreases by about one-third due to the more competitive association of $\mathrm{Br}^{-}$with TBA. For the latter solution, the interfacial $\mathrm{Br}^{-}$concentration reaches nearly $60 \%(0.9 \mathrm{M})$ of the corresponding solution without $\mathrm{NaCl}(1.6 \mathrm{M})$.

In Figure $2 \mathrm{~b}$, we observed a clear correlation between the uptake coefficient of $\mathrm{O}_{3}$ with the photoemission signal from the bromide ozonide intermediate. With the estimated interfacial bromide concentrations, we can assess the relationship between the uptake coefficient at $36 \mathrm{ppb}$ (where it is dominated by the surface reaction) and the interfacial bromide concentration (Figure 6). In the absence of $\mathrm{NaCl}$, the uptake coefficient, thus the overall turnover of $\mathrm{O}_{3}$ at the surface, increases by about $60 \%$. This is paralleled by a 20 -fold increase of the interfacial bromide concentration (red dotted arrow in Figure 6). In turn only a 3 -fold increase of the intermediate signal (Figure 2b) was observed. Even if taking into account a similar ratio between signal and concentration as for bromide, the steady state concentration of the intermediate increases by much less than that of bromide itself but still considerably more than the uptake coefficient. Therefore, limitations seem to be at work that prevent interfacial bromide from being more efficiently reacted in the presence of TBA. This could be related to limitations imposed by the high density of alkyl chains at the interface. However, a previous study has shown that even strongly ordered monolayers of fatty acids have permeabilities sufficiently large to allow uptake coefficients of $\mathrm{O}_{3} 2$ orders of magnitude larger than in the present work. ${ }^{72}$ Therefore, it is more likely that the stability of TBA-Br ion pairs lowers the reactivity with $\mathrm{O}_{3}$ to form the bromide ozonide intermediate. In addition, on the basis of the first order rate coefficients of the intermediate, $k_{\mathrm{s}}$ (last column of Table 1), which were retrieved from the fits to the kinetic data,

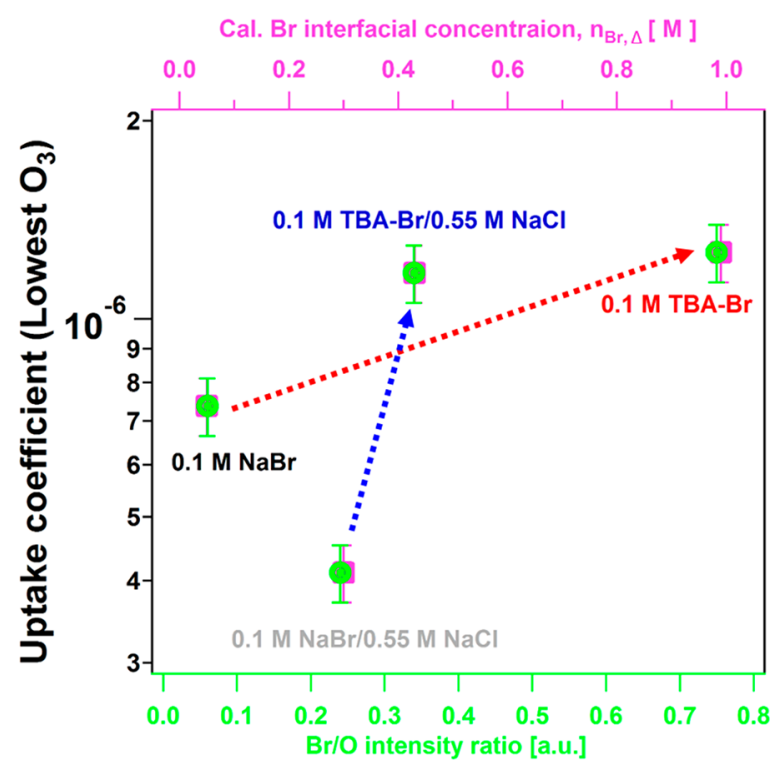

Figure 6. Uptake coefficient of $\mathrm{O}_{3}$ at $36 \mathrm{ppb}$ compared with the measured $\mathrm{Br}^{-} / \mathrm{O}$ intensity ratio (lower $x$-axis, green) and calculated $\mathrm{Br}^{-}$interfacial concentration (upper $x$-axis, pink) for four different aqueous solutions.

the presence of TBA affects the lifetime of the intermediate by about 1 order of magnitude when comparing $0.1 \mathrm{M} \mathrm{NaBr}$ and $0.1 \mathrm{M}$ TBA-Br. In the presence of $\mathrm{NaCl}$, but in the absence of TBA, in spite of the substantially increased interfacial bromide concentration, the uptake coefficient is $60 \%$ lower than that for pure $\mathrm{NaBr}$, which is more in line with the reduced abundance of the intermediate. Thus, even for this inorganic mixture, the abundances of bromide and of the bromide ozonide intermediate are not in accord with each other, which justifies further work. In the presence of TBA and $\mathrm{NaCl}$ combined, the uptake coefficient of $\mathrm{O}_{3}$ was nearly as high as that in the absence of $\mathrm{NaCl}$, even though the interfacial bromide concentration was almost $60 \%$ lower. This again indicates that the interfacial abundance of bromide is not the sole indicator for reactivity but rather that the details of how $\mathrm{O}_{3}$ may accommodate to the surface in the presence of TBA and the way the ozonide intermediate may be stabilized are important.

\section{CONCLUSION}

In this study, we measured the surface propensity of cationic tetrabutylammonium at the aqueous liquid-vapor interface by liquid microjet X-ray photoelectron spectroscopy and the effect of this surfactant on ozone uptake to aqueous bromide solutions. The positively charged nitrogen group in TBA, along with its surface activity, is leading to enhanced interfacial concentration of bromide and the $[\mathrm{Br} \cdot \mathrm{OOO}]^{-}$intermediate due to electrostatic interactions. In parallel, in kinetic experiments for the same system, a strongly enhanced ozone loss rate in the presence of TBA on the surface of bromide solutions was observed. An attenuation model was developed to account for the attenuation of photoelectrons by the carbonrich layer of the TBA surfactant. The more quantitative analysis demonstrates that $\mathrm{TBA}-\mathrm{Br}$ increases the local density of bromide ions by a factor of 20 above that of neat aqueous bromide solutions at the same bulk concentration. Similarly, mixing TBA-Br with $\mathrm{NaCl}$ at seawater concentration led to an interfacial bromide ion density enhanced by about $43 \%$ 
compared to the corresponding mixture of just $\mathrm{NaBr}$ and $\mathrm{NaCl}$. Still, the reaction rates of $\mathrm{O}_{3}$ with these solutions were not simply proportional to the interfacial bromide concentrations, as other effects, such as the different interfacial structure, or the stabilization of the reaction intermediate are additional factors influencing reactivity.

Aliphatic amines and amino acids are important positively charged surfactants at the sea surface microlayer (the topmost organic-rich layer), with average concentrations in the range 50-1500 $\mathrm{ng} \mathrm{L}^{-1}$. 12,36,73 This work shows that they may exert strong effects on halogen activation processes and their presence should be considered when it comes to assess the impact of halogen chemistry on the atmospheric oxidation capacity and the climate.

\section{ASSOCIATED CONTENT}

\section{SI Supporting Information}

The Supporting Information is available free of charge at https://pubs.acs.org/doi/10.1021/acsearthspacechem.1c00233.

Figures of valence spectra, $\mathrm{O} 1 \mathrm{~s}$ and $\mathrm{Br} 3 \mathrm{~d}$ photoelectron spectra, $\mathrm{O} 1 \mathrm{~s}$ and $\mathrm{C} 1 \mathrm{~s}$ photoemission spectra, ratio of $\mathrm{C} 1 \mathrm{~s}$ photoemission intensity of aliphatic carbon to that of amine coupled carbon, measured surface tension, and surface excess of TBA-Br, discussions of calculation of photoemission signal intensity ratios based on the attenuation model, surface excess of TBA-Br derived from surface tension measurements, and calculation of the uptake coefficient (PDF)

\section{AUTHOR INFORMATION}

\section{Corresponding Author}

Markus Ammann - Laboratory of Environmental Chemistry, Paul Scherrer Institute, 5232 Villigen, Switzerland;

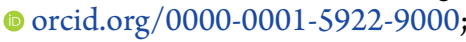

Email: markus.ammann@psi.ch

\section{Authors}

Shuzhen Chen - Laboratory of Environmental Chemistry, Paul Scherrer Institute, 5232 Villigen, Switzerland; Institute of Atmospheric and Climate Sciences, ETH Zürich, 8006 Zürich, Switzerland

Luca Artiglia - Laboratory of Environmental Chemistry, Paul Scherrer Institute, 5232 Villigen, Switzerland; 이이.org/ 0000-0003-4683-6447

Fabrizio Orlando - Laboratory of Environmental Chemistry, Paul Scherrer Institute, 5232 Villigen, Switzerland; Present Address: Omya International AG, Baslerstrasse 42, CH4665 Oftringen, Switzerland

Jacinta Edebeli - Laboratory of Environmental Chemistry, Paul Scherrer Institute, 5232 Villigen, Switzerland; Institute of Atmospheric and Climate Sciences, ETH Zürich, 8006 Zürich, Switzerland

Xiangrui Kong - Center for Atmospheric Research, University of Oulu, 90014 Oulu, Finland; Present

Address: Department of Chemistry and Molecular Biology, University of Gothenburg, 41296 Göteborg, Sweden.

Huanyu Yang - Laboratory of Environmental Chemistry, Paul Scherrer Institute, 5232 Villigen, Switzerland; Institute of Atmospheric and Climate Sciences, ETH Zürich, 8006 Zürich, Switzerland; ○ orcid.org/0000-0002-0927-9621
Anthony Boucly - Laboratory of Environmental Chemistry, Paul Scherrer Institute, 5232 Villigen, Switzerland; (1) orcid.org/0000-0003-1436-3462

Pablo Corral Arroyo - Laboratory of Environmental Chemistry, Paul Scherrer Institute, 5232 Villigen, Switzerland; Present Address: Department of Chemistry and Applied Biosciences, Laboratory of Physical Chemistry, ETH Zurich, Vladimir-Prelog-Weg 2, Zurich 8093, Switzerland.; 다이.org/0000-0003-4090-1623

Nønne Prisle - Center for Atmospheric Research, University of Oulu, 90014 Oulu, Finland; orcid.org/0000-0002-20416105

Complete contact information is available at:

https://pubs.acs.org/10.1021/acsearthspacechem.1c00233

\section{Author Contributions}

The manuscript was written through contributions of all authors. All authors have given approval to the final version of the manuscript.

\section{Funding}

This project was supported by the Swiss National Science Foundation (grant no 169176). This project received funding from the European Research Council (ERC) under the European Union's Horizon 2020 research and innovation program, Project SURFACE (grant agreement no. 717022). N.P. also gratefully acknowledges the financial contribution from the Academy of Finland, including grant nos. 308238, 314175 , and 335649.

\section{Notes}

The authors declare no competing financial interest.

\section{ACKNOWLEDGMENTS}

This work was performed at the SIM beamline of the Swiss Light Source, Paul Scherrer Institute, Villigen PSI, Switzerland. The authors would like to thank Dr. Xing Wang from University of Bern for helpful discussions on the attenuation modelling.

\section{REFERENCES}

(1) Abbatt, J. P. D.; Thomas, J. L.; Abrahamsson, K.; Boxe, C.; Granfors, A.; Jones, A. E.; King, M. D.; Saiz-Lopez, A.; Shepson, P. B.; Sodeau, J.; Toohey, D. W.; Toubin, C.; von Glasow, R.; Wren, S. N.; Yang, $\mathrm{X}$. Halogen activation via interactions with environmental ice and snow in the polar lower troposphere and other regions. Atmos. Chem. Phys. 2012, 12 (14), 6237-6271.

(2) Simpson, W. R.; Brown, S. S.; Saiz-Lopez, A.; Thornton, J. A.; von Glasow, R. Tropospheric Halogen Chemistry: Sources, Cycling, and Impacts. Chem. Rev. 2015, 115 (10), 4035-4062.

(3) Sherwen, T.; Evans, M. J.; Carpenter, L. J.; Schmidt, J. A.; Mickley, L. J. Halogen chemistry reduces tropospheric $\mathrm{O}_{3}$ radiative forcing. Atmos. Chem. Phys. 2017, 17 (2), 1557-1569.

(4) Carpenter, L. J.; MacDonald, S. M.; Shaw, M. D.; Kumar, R.; Saunders, R. W.; Parthipan, R.; Wilson, J.; Plane, J. M. C. Atmospheric iodine levels influenced by sea surface emissions of inorganic iodine. Nat. Geosci. 2013, 6 (2), 108-111.

(5) Wang, S.; Schmidt, J. A.; Baidar, S.; Coburn, S.; Dix, B.; Koenig, T. K.; Apel, E.; Bowdalo, D.; Campos, T. L.; Eloranta, E.; Evans, M. J.; DiGangi, J. P.; Zondlo, M. A.; Gao, R.-S.; Haggerty, J. A.; Hall, S. R.; Hornbrook, R. S.; Jacob, D.; Morley, B.; Pierce, B.; Reeves, M.; Romashkin, P.; ter Schure, A.; Volkamer, R. Active and widespread halogen chemistry in the tropical and subtropical free troposphere. Proc. Natl. Acad. Sci. U. S. A. 2015, 112 (30), 9281-9286. 
(6) Simpson, W. R.; Brown, S. S.; Saiz-Lopez, A.; Thornton, J. A.; von Glasow, R. Tropospheric Halogen Chemistry: Sources, Cycling, and Impacts. Chem. Rev. 2015, 115 (10), 4035-4062.

(7) Koenig, T. K.; Baidar, S.; Campuzano-Jost, P.; Cuevas, C. A.; Dix, B.; Fernandez, R. P.; Guo, H.; Hall, S. R.; Kinnison, D.; Nault, B. A.; Ullmann, K.; Jimenez, J. L.; Saiz-Lopez, A.; Volkamer, R. Quantitative detection of iodine in the stratosphere. Proc. Natl. Acad. Sci. U. S. A. 2020, 117 (4), 1860-1866.

(8) Abbatt, J. P. D.; Waschewsky, G. C. G. Heterogeneous Interactions of $\mathrm{HOBr}, \mathrm{HNO}_{3}, \mathrm{O}_{3}$, and $\mathrm{NO}_{2}$ with Deliquescent $\mathrm{NaCl}$ Aerosols at Room Temperature. J. Phys. Chem. A 1998, 102 (21), 3719-3725.

(9) Simpson, W. R.; von Glasow, R.; Riedel, K.; Anderson, P.; Ariya, P.; Bottenheim, J.; Burrows, J.; Carpenter, L. J.; Frieß, U.; Goodsite, M. E.; Heard, D.; Hutterli, M.; Jacobi, H. W.; Kaleschke, L.; Neff, B.; Plane, J.; Platt, U.; Richter, A.; Roscoe, H.; Sander, R.; Shepson, P.; Sodeau, J.; Steffen, A.; Wagner, T.; Wolff, E. Halogens and their role in polar boundary-layer ozone depletion. Atmos. Chem. Phys. 2007, 7 (16), 4375-4418.

(10) O’Dowd, C. D.; Facchini, M. C.; Cavalli, F.; Ceburnis, D.; Mircea, M.; Decesari, S.; Fuzzi, S.; Yoon, Y. J.; Putaud, J.-P. Biogenically driven organic contribution to marine aerosol. Nature 2004, 431 (7009), 676-680.

(11) Prather, K. A.; Bertram, T. H.; Grassian, V. H.; Deane, G. B.; Stokes, M. D.; DeMott, P. J.; Aluwihare, L. I.; Palenik, B. P.; Azam, F.; Seinfeld, J. H.; Moffet, R. C.; Molina, M. J.; Cappa, C. D.; Geiger, F. M.; Roberts, G. C.; Russell, L. M.; Ault, A. P.; Baltrusaitis, J.; Collins, D. B.; Corrigan, C. E.; Cuadra-Rodriguez, L. A.; Ebben, C. J.; Forestieri, S. D.; Guasco, T. L.; Hersey, S. P.; Kim, M. J.; Lambert, W. F.; Modini, R. L.; Mui, W.; Pedler, B. E.; Ruppel, M. J.; Ryder, O. S.; Schoepp, N. G.; Sullivan, R. C.; Zhao, D. Bringing the ocean into the laboratory to probe the chemical complexity of sea spray aerosol. Proc. Natl. Acad. Sci. U. S. A. 2013, 110 (19), 7550-7555.

(12) van Pinxteren, M.; Fomba, K. W.; Triesch, N.; Stolle, C.; Wurl, O.; Bahlmann, E.; Gong, X.; Voigtländer, J.; Wex, H.; Robinson, T. B.; Barthel, S.; Zeppenfeld, S.; Hoffmann, E. H.; Roveretto, M.; Li, C.; Grosselin, B.; Daële, V.; Senf, F.; van Pinxteren, D.; Manzi, M.; Zabalegui, N.; Frka, S.; Gašparović, B.; Pereira, R.; Li, T.; Wen, L.; Li, J.; Zhu, C.; Chen, H.; Chen, J.; Fiedler, B.; von Tümpling, W.; Read, K. A.; Punjabi, S.; Lewis, A. C.; Hopkins, J. R.; Carpenter, L. J.; Peeken, I.; Rixen, T.; Schulz-Bull, D.; Monge, M. E.; Mellouki, A.; George, C.; Stratmann, F.; Herrmann, H. Marine organic matter in the remote environment of the Cape Verde islands - an introduction and overview to the MarParCloud campaign. Atmos. Chem. Phys. 2020, 20 (11), 6921-6951.

(13) Mata, J.; Varade, D.; Ghosh, G.; Bahadur, P. Effect of tetrabutylammonium bromide on the micelles of sodium dodecyl sulfate. Colloids Surf., A 2004, 245 (1), 69-73.

(14) Cochran, R. E.; Ryder, O. S.; Grassian, V. H.; Prather, K. A. Sea Spray Aerosol: The Chemical Link between the Oceans, Atmosphere, and Climate. Acc. Chem. Res. 2017, 50 (3), 599-604.

(15) Ciuraru, R.; Fine, L.; van Pinxteren, M.; D’Anna, B.; Herrmann, H.; George, C. Photosensitized production of functionalized and unsaturated organic compounds at the air-sea interface. Sci. Rep. 2015, 5 (1), 12741.

(16) Alpert, P. A.; Ciuraru, R.; Rossignol, S.; Passananti, M.; Tinel, L.; Perrier, S.; Dupart, Y.; Steimer, S. S.; Ammann, M.; Donaldson, D. J.; George, C. Fatty Acid Surfactant Photochemistry Results in New Particle Formation. Sci. Rep. 2017, 7 (1), 12693.

(17) Ammann, M.; Cox, R. A.; Crowley, J. N.; Jenkin, M. E.; Mellouki, A.; Rossi, M. J.; Troe, J.; Wallington, T. J. Evaluated kinetic and photochemical data for atmospheric chemistry: Volume VI heterogeneous reactions with liquid substrates. Atmos. Chem. Phys. 2013, 13 (16), 8045-8228.

(18) Clifford, D.; Donaldson, D. J. Direct Experimental Evidence for a Heterogeneous Reaction of Ozone with Bromide at the AirAqueous Interface. J. Phys. Chem. A 2007, 111 (39), 9809-9814.

(19) Oldridge, N. W.; Abbatt, J. P. D. Formation of Gas-Phase Bromine from Interaction of Ozone with Frozen and Liquid $\mathrm{NaCl}$ /
NaBr Solutions: Quantitative Separation of Surficial Chemistry from Bulk-Phase Reaction. J. Phys. Chem. A 2011, 115 (12), 2590-2598.

(20) Artiglia, L.; Edebeli, J.; Orlando, F.; Chen, S.; Lee, M.-T.; Corral Arroyo, P.; Gilgen, A.; Bartels-Rausch, T.; Kleibert, A.; Vazdar, M.; Andres Carignano, M.; Francisco, J. S.; Shepson, P. B.; Gladich, I.; Ammann, M. A surface-stabilized ozonide triggers bromide oxidation at the aqueous solution-vapour interface. Nat. Commun. 2017, 8 (1), 700 .

(21) Edebeli, J.; Ammann, M.; Bartels-Rausch, T. Microphysics of the aqueous bulk counters the water activity driven rate acceleration of bromide oxidation by ozone from 289-245 K. Environ. Sci.: Processes Impacts 2019, 21 (1), 63-73.

(22) Sakamoto, Y.; Goda, M.; Hirokawa, J. Kinetics Study of Heterogeneous Bromine Release from the Reaction between Gaseous Ozone and Aqueous Bromide Solution. J. Phys. Chem. A 2018, 122 (10), 2723-2731.

(23) Jung, Y.; Hong, E.; Kwon, M.; Kang, J.-W. A kinetic study of ozone decay and bromine formation in saltwater ozonation: Effect of $\mathrm{O}_{3}$ dose, salinity, pH, and temperature. Chem. Eng. J. 2017, 312, 3038.

(24) Moreno, C.; Baeza-Romero, M. T. A kinetic model for ozone uptake by solutions and aqueous particles containing $\mathrm{I}^{-}$and $\mathrm{Br}^{-}$, including seawater and sea-salt aerosol. Phys. Chem. Chem. Phys. 2019, 21 (36), 19835-19856.

(25) Hunt, S. W.; Roeselová, M.; Wang, W.; Wingen, L. M.; Knipping, E. M.; Tobias, D. J.; Dabdub, D.; Finlayson-Pitts, B. J. Formation of Molecular Bromine from the Reaction of Ozone with Deliquesced $\mathrm{NaBr}$ Aerosol: Evidence for Interface Chemistry. J. Phys. Chem. A 2004, 108 (52), 11559-11572.

(26) Oum, K. W.; Lakin, M. J.; Finlayson-Pitts, B. J. Bromine activation in the troposphere by the dark reaction of $\mathrm{O}_{3}$ with seawater ice. Geophys. Res. Lett. 1998, 25 (21), 3923-3926.

(27) Liu, Q.; Schurter, L. M.; Muller, C. E.; Aloisio, S.; Francisco, J. S.; Margerum, D. W. Kinetics and Mechanisms of Aqueous Ozone Reactions with Bromide, Sulfite, Hydrogen Sulfite, Iodide, and Nitrite Ions. Inorg. Chem. 2001, 40 (17), 4436-4442.

(28) Donaldson, D. J.; Anderson, D. Does molecular $\mathrm{HNO}_{3}$ adsorb onto sulfuric acid droplet surfaces? Geophys. Res. Lett. 1999, 26 (24), $3625-3628$.

(29) Ammann, M.; Artiglia, L.; Bartels-Rausch, T. Chapter 6 - X-Ray Excited Electron Spectroscopy to Study Gas-Liquid Interfaces of Atmospheric Relevance. In Physical Chemistry of Gas-Liquid Interfaces; Faust, J. A., House, J. E., Eds.; Elsevier, 2018; pp 135-166.

(30) Öhrwall, G.; Prisle, N. L.; Ottosson, N.; Werner, J.; Ekholm, V.; Walz, M.-M.; Björneholm, O. Acid-Base Speciation of Carboxylate Ions in the Surface Region of Aqueous Solutions in the Presence of Ammonium and Aminium Ions. J. Phys. Chem. B 2015, 119 (10), 4033-4040.

(31) Prisle, N.; Ottosson, N.; Öhrwall, G.; Söderström, J.; Maso, M. D.; Björneholm, O. Surface/bulk partitioning and acid/base speciation of aqueous decanoate: direct observations and atmospheric implications. Atmos. Chem. Phys. 2012, 12 (24), 12227-12242.

(32) Lee, M.-T.; Brown, M. A.; Kato, S.; Kleibert, A.; Türler, A.; Ammann, M. Competition between organics and bromide at the aqueous solution-air interface as seen from ozone uptake kinetics and X-ray photoelectron spectroscopy. J. Phys. Chem. A 2015, 119 (19), 4600-4608.

(33) Lee, M.-T.; Orlando, F.; Khabiri, M.; Roeselová, M.; Brown, M. A.; Ammann, M. The opposing effect of butanol and butyric acid on the abundance of bromide and iodide at the aqueous solution-air interface. Phys. Chem. Chem. Phys. 2019, 21 (16), 8418-8427.

(34) Gladich, I.; Chen, S.; Vazdar, M.; Boucly, A.; Yang, H.; Ammann, M.; Artiglia, L. Surface Propensity of Aqueous Atmospheric Bromine at the Liquid-Gas Interface. J. Phys. Chem. Lett. 2020, 11 (9), 3422-3429.

(35) Lee, M.-T.; Brown, M. A.; Kato, S.; Kleibert, A.; Türler, A.; Ammann, M. Competition between Organics and Bromide at the Aqueous Solution-Air Interface as Seen from Ozone Uptake Kinetics 
and X-ray Photoelectron Spectroscopy. J. Phys. Chem. A 2015, 119 (19), 4600-4608.

(36) Ge, X.; Wexler, A. S.; Clegg, S. L. Atmospheric amines - Part I. A review. Atmos. Environ. 2011, 45 (3), 524-546.

(37) Ohtani, N.; Ohta, T.; Hosoda, Y.; Yamashita, T. Phase Behavior and Phase-Transfer Catalysis of Tetrabutylammonium Salts. InterfaceMediated Catalysis. Langmuir 2004, 20 (2), 409-415.

(38) Winter, B.; Weber, R.; Schmidt, P. M.; Hertel, I. V.; Faubel, M.; Vrbka, L.; Jungwirth, P. Molecular Structure of Surface-Active Salt Solutions: Photoelectron Spectroscopy and Molecular Dynamics Simulations of Aqueous Tetrabutylammonium Iodide. J. Phys. Chem. B 2004, 108 (38), 14558-14564.

(39) Winter, B.; Weber, R.; Hertel, I. V.; Faubel, M.; Vrbka, L.; Jungwirth, P. Effect of bromide on the interfacial structure of aqueous tetrabutylammonium iodide: Photoelectron spectroscopy and molecular dynamics simulations. Chem. Phys. Lett. 2005, 410 (4), 222-227.

(40) Karashima, S.; Suzuki, T. Charge-Transfer-to-Solvent Reaction in a Hydrophobic Tetrabutylammonium Iodide Molecular Layer in Aqueous Solution. J. Phys. Chem. B 2019, 123 (17), 3769-3775.

(41) Watanabe, I.; Takahashi, N.; Tanida, H. Dehydration of iodide segregated by tetraalkylammonium at the air/solution interface studied by photoelectron emission spectroscopy. Chem. Phys. Lett. 1998, 287 (5), 714-718.

(42) Sobyra, T. B.; Pliszka, H.; Bertram, T. H.; Nathanson, G. M. Production of $\mathrm{Br}_{2}$ from $\mathrm{N}_{2} \mathrm{O}_{5}$ and $\mathrm{Br}-$ in Salty and Surfactant-Coated Water Microjets. J. Phys. Chem. A 2019, 123 (41), 8942-8953.

(43) Shaloski, M. A.; Gord, J. R.; Staudt, S.; Quinn, S. L.; Bertram, T. H.; Nathanson, G. M. Reactions of $\mathrm{N}_{2} \mathrm{O}_{5}$ with Salty and SurfactantCoated Glycerol: Interfacial Conversion of $\mathrm{Br}^{-}$to $\mathrm{Br}_{2}$ Mediated by Alkylammonium Cations. J. Phys. Chem. A 2017, 121 (19), 37083719.

(44) Flechsig, U.; Nolting, F.; Fraile Rodriguez, A.; Krempasky, J.; Quitmann, C.; Schmidt, T.; Spielmann, S.; Zimoch, D.; Garrett, R.; Gentle, I.; Nugent, K.; Wilkins, S. Performance Measurements at the SLS SIM Beamline. AIP Conf. Proc. 2009, 1234, 319-322.

(45) Brown, M. A.; Redondo, A. B.; Jordan, I.; Duyckaerts, N.; Lee, M.-T.; Ammann, M.; Nolting, F.; Kleibert, A.; Huthwelker, T.; Mächler, J.-P.; Birrer, M.; Honegger, J.; Wetter, R.; Wörner, H. J.; Bokhoven, J. A. v. A new endstation at the Swiss Light Source for ultraviolet photoelectron spectroscopy, X-ray photoelectron spectroscopy, and X-ray absorption spectroscopy measurements of liquid solutions. Rev. Sci. Instrum. 2013, 84 (7), 073904.

(46) Winter, B.; Weber, R.; Widdra, W.; Dittmar, M.; Faubel, M.; Hertel, I. V. Full Valence Band Photoemission from Liquid Water Using EUV Synchrotron Radiation. J. Phys. Chem. A 2004, 108 (14), 2625-2632.

(47) Yeh, J. J.; Lindau, I. Atomic subshell photoionization cross sections and asymmetry parameters: $1 \leqslant \mathrm{Z} \leqslant 103$. At. Data Nucl. Data Tables 1985, 32 (1), 1-155.

(48) Ottosson, N.; Faubel, M.; Bradforth, S. E.; Jungwirth, P.; Winter, B. Photoelectron spectroscopy of liquid water and aqueous solution: Electron effective attenuation lengths and emission-angle anisotropy. J. Electron Spectrosc. Relat. Phenom. 2010, 177 (2-3), 6070.

(49) Schneider, S. R.; Lakey, P. S. J.; Shiraiwa, M.; Abbatt, J. P. D. Reactive Uptake of Ozone to Simulated Seawater: Evidence for Iodide Depletion. J. Phys. Chem. A 2020, 124 (47), 9844-9853.

(50) Pruyne, J. G.; Lee, M.-T.; Fábri, C.; Beloqui Redondo, A.; Kleibert, A.; Ammann, M.; Brown, M. A.; Krisch, M. J. Liquid-Vapor Interface of Formic Acid Solutions in Salt Water: A Comparison of Macroscopic Surface Tension and Microscopic in Situ X-ray Photoelectron Spectroscopy Measurements. J. Phys. Chem. C 2014, 118 (50), 29350-29360.

(51) Lee, M.-T.; Orlando, F.; Artiglia, L.; Chen, S.; Ammann, M. Chemical Composition and Properties of the Liquid-Vapor Interface of Aqueous C1 to C4 Monofunctional Acid and Alcohol Solutions. J. Phys. Chem. A 2016, 120 (49), 9749-9758.
(52) Walz, M. M.; Werner, J.; Ekholm, V.; Prisle, N. L.; Öhrwall, G.; Björneholm, O. Alcohols at the aqueous surface: chain length and isomer effects. Phys. Chem. Chem. Phys. 2016, 18 (9), 6648-6656.

(53) Toribio, A. R.; Prisle, N. L.; Wexler, A. S. Statistical Mechanics of Multilayer Sorption: Surface Concentration Modeling and XPS Measurement. J. Phys. Chem. Lett. 2018, 9 (6), 1461-1464.

(54) Ottosson, N.; Wernersson, E.; Söderström, J.; Pokapanich, W.; Kaufmann, S.; Svensson, S.; Persson, I.; Öhrwall, G.; Björneholm, O. The protonation state of small carboxylic acids at the water surface from photoelectron spectroscopy. Phys. Chem. Chem. Phys. 2011, 13 (26), 12261-12267.

(55) Bhowmik, D.; Malikova, N.; Mériguet, G.; Bernard, O.; Teixeira, J.; Turq, P. Aqueous solutions of tetraalkylammonium halides: ion hydration, dynamics and ion-ion interactions in light of steric effects. Phys. Chem. Chem. Phys. 2014, 16 (26), 13447-13457.

(56) Shah, A.-u.-H. A.; Ali, K.; Bilal, S. Surface tension, surface excess concentration, enthalpy and entropy of surface formation of aqueous salt solutions. Colloids Surf., A 2013, 417, 183-190.

(57) Ottosson, N.; Vácha, R.; Aziz, E. F.; Pokapanich, W.; Eberhardt, W.; Svensson, S.; Öhrwall, G.; Jungwirth, P.; Björneholm, O.; Winter, B. Large variations in the propensity of aqueous oxychlorine anions for the solution/vapor interface. J. Chem. Phys. 2009, 131 (12), 124706.

(58) Olivieri, G.; Parry, K. M.; D’Auria, R.; Tobias, D. J.; Brown, M. A. Specific Anion Effects on $\mathrm{Na}^{+}$Adsorption at the Aqueous Solution-Air Interface: MD Simulations, SESSA Calculations, and Photoelectron Spectroscopy Experiments. J. Phys. Chem. B 2018, 122 (2), 910-918.

(59) Eschen, F.; Heyerhoff, M.; Morgner, H.; Vogt, J. The concentration-depth profile at the surface of a solution of tetrabutylammonium iodide in formamide, based on angle-resolved photoelectron spectroscopy. J. Phys.: Condens. Matter 1995, 7 (10), 1961-1978.

(60) Bergersen, H.; Marinho, R. R. T.; Pokapanich, W.; Lindblad, A.; Björneholm, O.; Sæthre, L. J.; Öhrwall, G. A photoelectron spectroscopic study of aqueous tetrabutylammonium iodide. J. Phys.: Condens. Matter 2007, 19 (32), 326101.

(61) Woods, E.; Konys, C. A.; Rossi, S. R. Photoemission of Iodide from Aqueous Aerosol Particle Surfaces. J. Phys. Chem. A 2019, 123 (13), 2901-2907.

(62) Zhao, X.; Nathanson, G. M.; Andersson, G. G. Experimental Depth Profiles of Surfactants, Ions, and Solvent at the Angstrom Scale: Studies of Cationic and Anionic Surfactants and their Salting Out. J. Phys. Chem. B 2020, 124 (11), 2218-2229.

(63) Walz, M. M.; Caleman, C.; Werner, J.; Ekholm, V.; Lundberg, D.; Prisle, N. L.; Ohrwall, G.; Bjorneholm, O. Surface behavior of amphiphiles in aqueous solution: a comparison between different pentanol isomers. Phys. Chem. Chem. Phys. 2015, 17 (21), 1403614044.

(64) Ghosal, S.; Brown, M. A.; Bluhm, H.; Krisch, M. J.; Salmeron, M.; Jungwirth, P.; Hemminger, J. C. Ion Partitioning at the Liquid/ Vapor Interface of a Multicomponent Alkali Halide Solution: A Model for Aqueous Sea Salt Aerosols. J. Phys. Chem. A 2008, 112 (48), 12378-12384.

(65) Toivola, M.; Prisle, N. L.; Elm, J.; Waxman, E. M.; Volkamer, R.; Kurtén, T. Can COSMOTherm Predict a Salting in Effect? J. Phys. Chem. A 2017, 121 (33), 6288-6295.

(66) Endo, S.; Pfennigsdorff, A.; Goss, K.-U. Salting-Out Effect in Aqueous $\mathrm{NaCl}$ Solutions: Trends with Size and Polarity of Solute Molecules. Environ. Sci. Technol. 2012, 46 (3), 1496-1503.

(67) Krisch, M. J.; D’Auria, R.; Brown, M. A.; Tobias, D. J.; Hemminger, C.; Ammann, M.; Starr, D. E.; Bluhm, H. The Effect of an Organic Surfactant on the Liquid-Vapor Interface of an Electrolyte Solution. J. Phys. Chem. C 2007, 111 (36), 13497-13509.

(68) Sawada, K.; Takahashi, E.; Horie, T.; Satoh, K. Solvent Effects on Ion-Pair Distribution and Dimerization of Tetraalkylammonium Salts. Monatsh. Chem. 2001, 132 (11), 1439-1450.

(69) Tomar, P. A.; Kolhapurkar, R. R.; Dagade, D. H.; Patil, K. J. Equilibrium Constant Studies for Complexation between Ammonium 
Ions and 18-Crown-6 in Aqueous Solutions at 298.15 K. J. Solution Chem. 2007, 36 (2), 193-209.

(70) Moberg, R.; Boekman, F.; Bohman, O.; Siegbahn, H. O. G. ESCA studies of phase-transfer catalysts in solution: ion pairing and surface activity. J. Am. Chem. Soc. 1991, 113 (10), 3663-3667.

(71) Mbuna, J.; Takayanagi, T.; Oshima, M.; Motomizu, S. Evaluation of weak ion association between tetraalkylammonium ions and inorganic anions in aqueous solutions by capillary zone electrophoresis. J. Chromatogr. A 2004, 1022 (1), 191-200.

(72) Rouvière, A.; Ammann, M. The effect of fatty acid surfactants on the uptake of ozone to aqueous halogenide particles. Atmos. Chem. Phys. 2010, 10 (23), 11489-11500.

(73) van Pinxteren, M.; Müller, C.; Iinuma, Y.; Stolle, C.; Herrmann, H. Chemical Characterization of Dissolved Organic Compounds from Coastal Sea Surface Microlayers (Baltic Sea, Germany). Environ. Sci. Technol. 2012, 46 (19), 10455-10462. 